\title{
Space Transportation Infrastructure Supported By Propellant Depots
}

\author{
David Smitherman ${ }^{1}$ \\ NASA Marshall Space Flight Center, ED04, Huntsville, Alabama, 35802, U.S.A. \\ and \\ Gordon Woodcock ${ }^{2}$ \\ Gray Research, Engineering, Science, and Technical Services Contract, \\ 655 Discovery Drive Ste. 300, Huntsville, AL 35806 U.S.A.
}

\begin{abstract}
A space transportation infrastructure is described that utilizes propellant depots to support all foreseeable missions in the Earth-Moon vicinity and deep space out to Mars. The infrastructure utilizes current expendable launch vehicles such as the Delta IV Heavy, Atlas V, and Falcon 9, for all crew, cargo, and propellant launches to orbit. Propellant launches are made to a Low-Earth-Orbit (LEO) Depot and an Earth-Moon Lagrange Point 1 (L1) Depot to support new reusable in-space transportation vehicles. The LEO Depot supports missions to Geosynchronous Earth Orbit (GEO) for satellite servicing, and to L1 for L1 Depot missions. The L1 Depot supports Lunar, Earth-Sun L2 (ESL2), Asteroid, and Mars missions. A Mars Orbital Depot is also described to support ongoing Mars missions.

New concepts for vehicle designs are presented that can be launched on current 5-meter diameter expendable launch vehicles. These new reusable vehicle concepts include a LEO Depot, L1 Depot, and Mars Orbital Depot based on International Space Station (ISS) heritage hardware. The high-energy depots at $\mathrm{L} 1$ and Mars orbit are compatible with, but do not require, electric propulsion tug use for propellant and/or cargo delivery. New reusable in-space crew transportation vehicles include a Crew Transfer Vehicle (CTV) for crew transportation between the LEO Depot and the L1 Depot, a new reusable Lunar Lander for crew transportation between the L1 Depot and the lunar surface, and a Deep Space Habitat (DSH) to support crew missions from the L1 Depot to ESL2, Asteroid, and Mars destinations. A 6 meter diameter Mars lander concept is presented that can be launched without a fairing based on the Delta IV heavy Payload Planners Guide, which indicates feasibility of a 6.5 meter fairing. This lander would evolve to re-usable operations when propellant production is established on Mars.

Figure 1 provides a summary of the possible missions this infrastructure can support. Summary mission profiles are presented for each primary mission capability. These profiles are the basis for propellant loads, numbers of vehicles/stages and launches for each mission capability. Data includes the number of launches required for each mission utilizing current expendable launch vehicle systems, and concluding remarks include ideas for reducing the number of launches through incorporation of heavy-lift launch vehicles, solar electric propulsion, and other transportation support concepts.
\end{abstract}

\footnotetext{
${ }^{1}$ Technical Manager, Advanced Concepts Office, David.Smitherman@nasa.gov, Senior Member AIAA

${ }^{2}$ Mission and Systems Analyst, Gray Research/ESTS, grw33@,comcast.net, AIAA Associate Fellow 


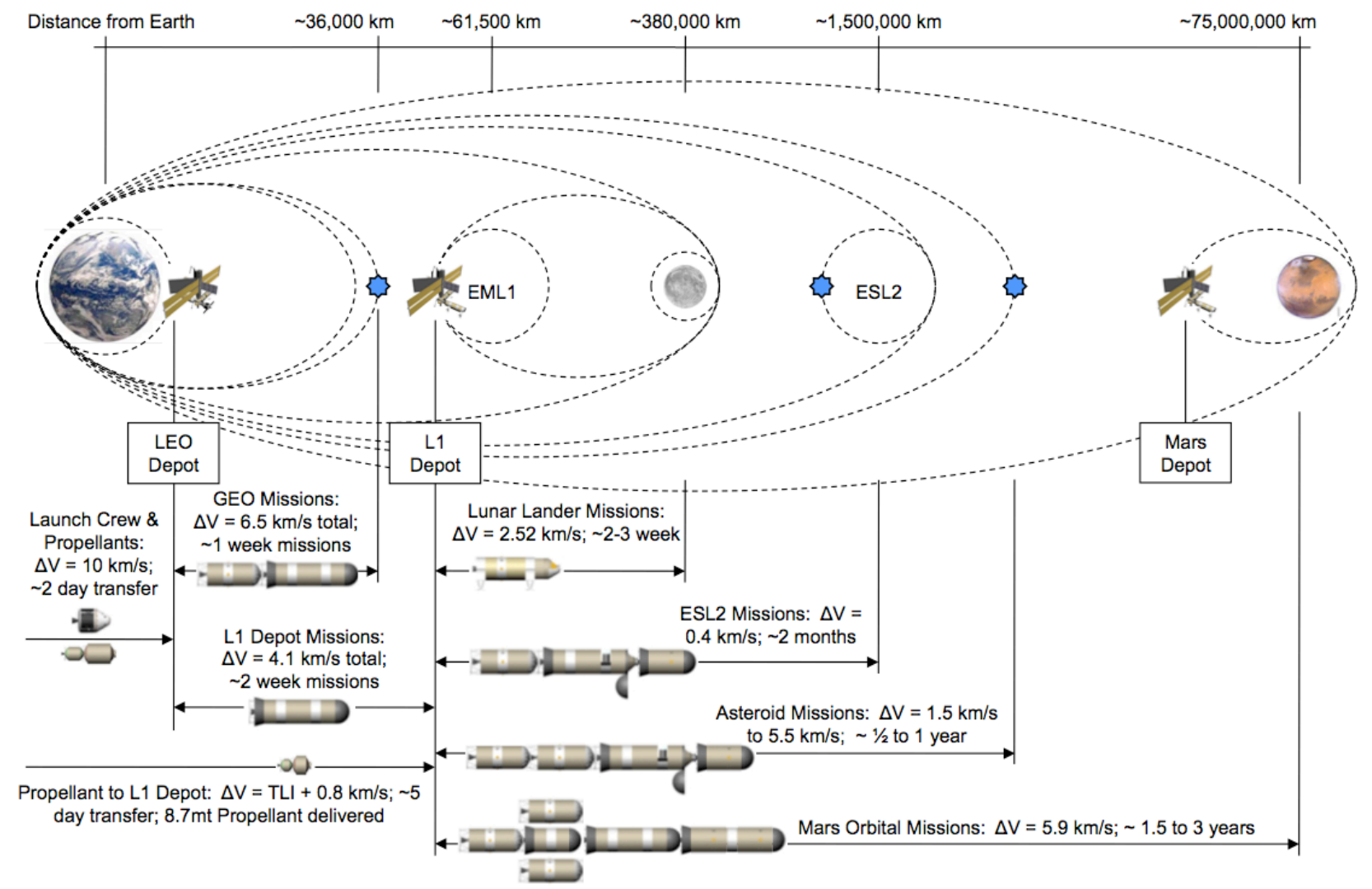

Figure 1. Space Infrastructure Overview. Potential destinations supported by current expendable launch vehicles and a new reusable in-space transportation infrastructure.

American Institute of Aeronautics and Astronautics 


\title{
Space Transportation Infrastructure Supported By Propellant Depots
}

\author{
David Smitherman ${ }^{a}$ \\ NASA Marshall Space Flight Center, ED04, Huntsville, Alabama, 35802, U.S.A. \\ And \\ Gordon Woodcock ${ }^{b}$ \\ Gray Research, Engineering, Science, and Technical Services Contract, \\ 655 Discovery Drive Suite 300, Huntsville, AL, 35806, U.S.A.
}

\begin{abstract}
A space transportation infrastructure is described that utilizes propellant depot servicing platforms to support all foreseeable missions in the Earth-Moon vicinity and deep space out to Mars. The infrastructure utilizes current expendable launch vehicle (ELV) systems such as the Delta IV Heavy, Atlas V, and Falcon 9, for all crew, cargo, and propellant launches to orbit. Propellant launches are made to a Low-Earth-Orbit (LEO) Depot and an Earth-Moon Lagrange Point 1 (L1) Depot to support new reusable in-space transportation vehicles. The LEO Depot supports missions to Geosynchronous Earth Orbit (GEO) for satellite servicing, and to L1 for L1 Depot missions. The L1 Depot supports Lunar, Earth-Sun L2 (ESL2), Asteroid, and Mars missions. New vehicle design concepts are presented that can be launched on current 5-meter diameter ELV systems. These new reusable vehicle concepts include a Crew Transfer Vehicle (CTV) for crew transportation between the LEO Depot, L1 Depot and missions beyond L1; a new reusable Lunar Lander for crew transportation between the L1 Depot and the lunar surface; and a new reusable Deep Space Habitat (DSH) with a CTV to support crew missions from the L1 Depot to ESL2, Asteroids, and a Mars Orbital Depot. The LEO Depot, L1 Depot, and Mars Orbital Depot are based on International Space Station (ISS) heritage hardware. Data provided includes the number of launches required for each mission utilizing current ELV systems (Delta IV Heavy or equivalent) and the approximate vehicle masses and propellant requirements. Also included is a discussion on affordability with ideas on technologies that could reduce the number of launches required and thoughts on how this infrastructure might be implemented incrementally over the next few decades. The potential benefits of this propellant depot infrastructure include competitive bidding for ELV flights and propellant services, development of new reusable in-space vehicles, and development of a multiuse infrastructure that can support many government and commercial missions simultaneously.
\end{abstract}

\section{Introduction}

$\mathrm{F}$ ROM 1967 to 1973 , NASA utilized the Saturn $\mathrm{V}^{1}$ as a heavy-lift launch vehicle for human missions to the Moon. The gross lift-off mass was $\sim 3,039,000 \mathrm{~kg}$ with a total payload mass of $\sim 45,018 \mathrm{~kg}$ and a propulsion and propellant mass of $\sim 2,993,982 \mathrm{~kg}$. The payloads consisted of a $3.9 \mathrm{~m}$ diameter Command Module ${ }^{2}$ at $\sim 5,809 \mathrm{~kg}$, a $3.9 \mathrm{~m}$ diameter Service Module at $24,523 \mathrm{~kg}$, and a $4.3 \mathrm{~m}$ diameter Lunar Module ${ }^{3}$ in its folded configuration at $14,696 \mathrm{~kg}$ including propellants and consumables in each. It is noteworthy that approximately $98.5 \%$ of the Saturn V mass was propellant and propulsion systems. Today, the remaining $1.5 \%$ payload mass could be broken down and launched on current commercially available ELV systems. This means that space transportation is not a payload delivery problem; it is a propellant and propulsion management problem. Here enters the idea for propellant depots in an infrastructure that can provide the same capabilities as the Saturn V for lunar missions, but with more flexibility to accommodate a variety of other missions simultaneously. The following sections provide a scenario on how our current commercially available ELV infrastructure with the addition of propellant depots can hypothetically

\footnotetext{
${ }^{a}$ Technical Manager, Advanced Concepts Office, David.Smitherman@nasa.gov, AIAA Senior Member

${ }^{\mathrm{b}}$ Mission and Systems Analyst, Gray Research/ESTS, grw33@comcast.net, AIAA Associate Fellow 
provide for $98.5 \%$ of the infrastructure, the propulsion and propellant, to support simultaneously all of our commercial and exploration mission needs for the foreseeable future.

\section{Infrastructure Summary}

The primary goal of this investigation was to determine the potential benefits of an in-space propellant depot infrastructure and develop a technically feasible system at a conceptual level. This was done by developing a space transportation concept that utilized existing ELV systems and new reusable in-space vehicles, supported by propellant depots to the greatest extent possible, that could be developed incrementally and put in service over time. Figure 1 provides a graphical summary of the infrastructure and the possible missions this infrastructure could support. It includes three depots, one each in LEO, L1, and Mars orbit, to support human missions to all destinations of interest out to Mars. Crew transportation includes commercial crew launch services to the LEO Depot and then a standard reusable CTV for crew transfers to the L1 Depot. The L1 Depot supports a reusable Lunar Lander for missions to the lunar surface and a reusable DSH in combination with a CTV for transfers to ESL2, Asteroids, and Mars orbit. Propellant deliveries to refuel these vehicles are launched directly to the LEO and L1 depots respectively. In addition to propellant supply, the depots are servicing platforms where propellant is stored and transferred to the reusable vehicles as needed, vehicle maintenance and upgrades can be accomplished, and crews with their logistics and payloads can be transferred between vehicles. Development of this infrastructure begins with the LEO Depot and grows incrementally for access to L1, the Moon, and then Mars. The LEO depot is used repeatedly for all human missions, and the L1 Depot is used repeatedly for all human Lunar, ESL2, Asteroid, and Mars missions. This operating scenario makes the depots and reusable vehicles part of a permanent infrastructure that could eventually support dozens of missions simultaneously, both commercial and exploration oriented, for decades into the future.

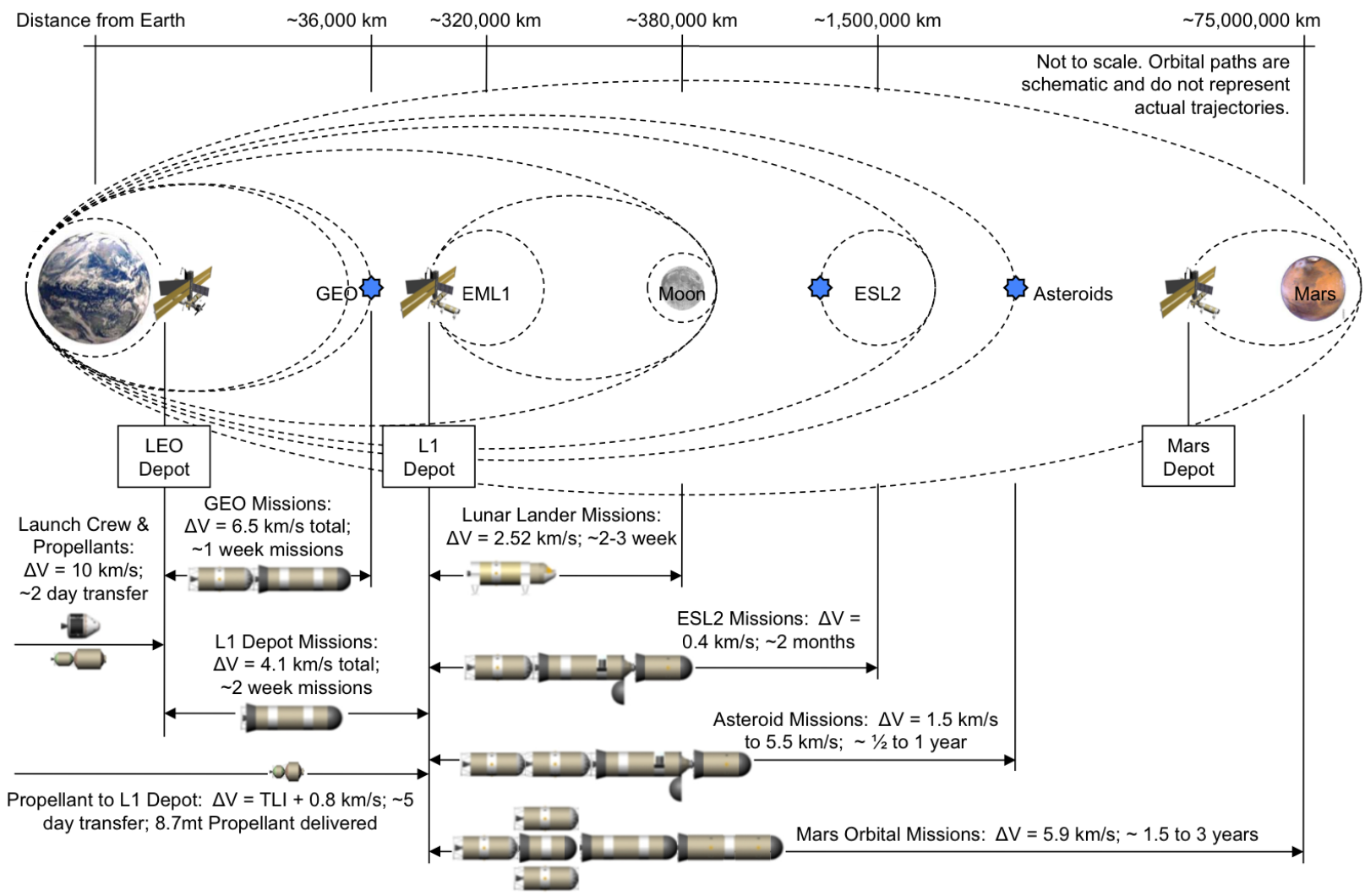

Figure 1. Space Infrastructure Overview. Potential destinations are shown utilizing current ELV systems and a new reusable in-space transportation infrastructure supported by propellant depots. 


\section{A. LEO Infrastructure Buildup}

Satellite servicing could be the initial capability using a reusable CTV and a Reusable Upper Stage (RUS) operating out of a LEO Depot. Figure 2 provides a graphic representation of how the LEO Depot infrastructure could support GEO satellite servicing, and Appendix A-1 provides a reference profile for assumed vehicle mass and propellant calculations. Three propellant launches deliver $\sim 64$ metric tons $(\mathrm{mt})$ of propellant to the LEO Depot to refuel a reusable CTV and a RUS, which hold $\sim 32 \mathrm{mt}$ of propellant each. The crew travels to the depot with one launch of a commercial crew return vehicle (CRV) and transfers into the CTV along with logistics and payloads for the servicing mission. Each mission to a GEO destination requires four launches. The RUS is docked to the CTV and is utilized for the insertion burn into a GEO transfer orbit. It utilizes $\sim 30 \mathrm{mt}$ of propellant in the boost phase with the remaining $\sim 2 \mathrm{mt}$ used for return of the RUS to the LEO Depot to support the next mission. Propulsive capture is utilized so no heat shield is required on the RUS for the return trip. The CTV utilizes $\sim 21.8 \mathrm{mt}$ of propellant to complete the transfer and rendezvous with the GEO satellite. After completion of the servicing mission the remaining $\sim 10.2 \mathrm{mt}$ of propellant is utilized for return to the LEO Depot. The return velocity from GEO is such that a heat shield is required for an aerocapture maneuver into LEO. Initial government servicing missions utilizing this infrastructure could include access to the Hubble Space Telescope, TDRSS ${ }^{\mathrm{c}}$ satellites, and other government and commercial satellites out to GEO. Initial commercial missions could include reusable robotic and human servicing vehicles for capture and relocation of dead satellites, assisting active satellites with failed upper stages, human servicing of GEO satellites, assisting expended propulsion systems, and expansion of the depot for other services such as commercial space travel, microgravity research, product development, and tourism.

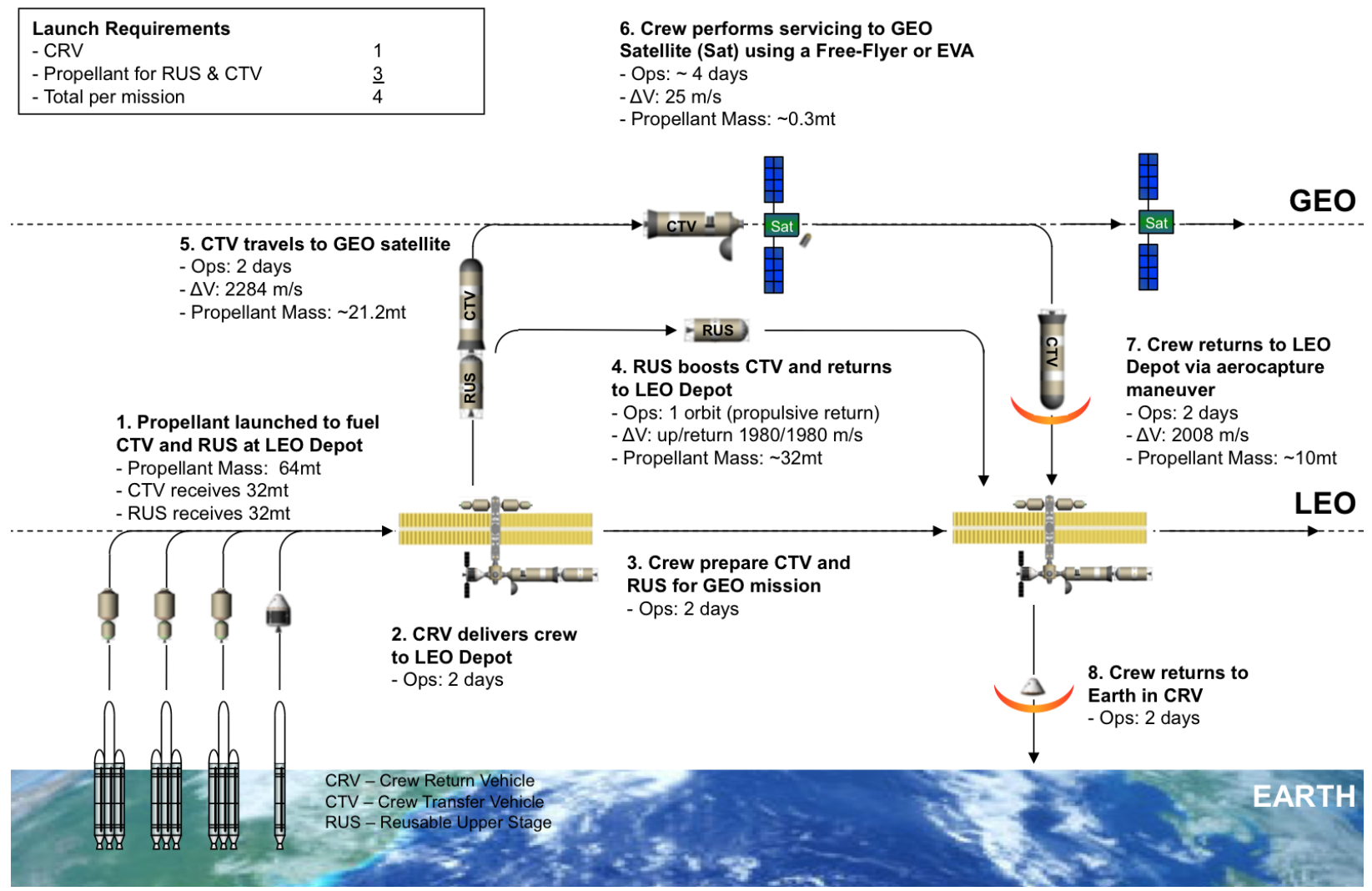

Figure 2. GEO Satellite Servicing. With a LEO Depot, a Reusable Upper Stage, and a reusable Crew Transfer Vehicle, human satellite servicing missions can be done as needed with 3 propellant launches and 1 crew launch per mission. See Appendix A-1 for GEO Satellite Servicing Reference Profile details.

${ }^{\mathrm{c}}$ Tracking and Data Relay Satellite System (TDRSS)

American Institute of Aeronautics and Astronautics 
The propellant depots envisioned for this infrastructure are based on ISS heritage hardware. Figure 3 illustrates a conceptual layout for the LEO Depot. It is similar in size to the ISS when it was under construction and had only one set of solar arrays in place. The ISS orbits the Earth at a $\sim 400 \mathrm{~km}$ altitude and a 51.6-degree inclination. The LEO Depot is envisioned to orbit the Earth under the ISS at a $\sim 350 \mathrm{~km}$ altitude and a $\sim 28.5$-degree inclination. An approximate mass for the LEO Depot was estimated based on ISS hardware at $\sim 43.5 \mathrm{mt}$. This infrastructure element is established in four launches, which includes: the depot truss section with attachments, the depot pressurized Node module, an RUS, and a CTV. An additional CRV crew mission can be included if human assembly operations are needed as done for the ISS. The truss section is designed to handle all power and propellant requirements such that a variety of vehicles can dock to the truss for propellant transfer. The pressurized Node element is designed to handle transfers between all crew vehicles and to support servicing utilizing an airlock for extra-vehicular activity (EVA) and/or a pressurized human Free-Flyer vehicle. Each end of the platform is expandable by adding a truss section for additional power and propellant transfer capabilities at one end, and additional pressurized modules added to the Node at the other end.

The RUS has a dry-mass of $\sim 4,300 \mathrm{~kg}$ and can hold $\sim 32 \mathrm{mt}$ of propellant. It is equipped with a docking adapter for propellant transfer and a structural truss adapter for attachment to the aft end of the CTV. Future RUS missions from the L1 Depot indicate that variations of the RUS could use structural truss adapters at both ends for multiple RUS stages and the addition of aerocapture features with a spherical nose and tail flare for return from higher energy orbits. An aerocapture system was estimated to add $\sim 4,500 \mathrm{~kg}$ mass.

The CTV and the RUS hold $\sim 32 \mathrm{mt}$ of propellant each and are filled at the LEO Depot from ongoing propellant flights from a variety of vehicles with the largest capacity being $22 \mathrm{mt}$ delivered by the Delta IV Heavy and perhaps larger propellant loads by a future Falcon Heavy. This flexibility in propellant delivery means propellants can be taken out of the critical path for vehicle sizing of each mission. Propellant can be collected on-orbit by contract from several sources, moving the largest part of the mission mass, the propellants and launch systems, into a competitive bid environment. This should have great potential for lowering overall mission cost and should help promote the commercial development of reusable launch systems for propellant delivery and other services.

The initial vehicles described here for propellant delivery include at least one reusable $\sim 32 \mathrm{mt}$ storage tanker with an active cooling system that stays at the depot with the remaining tankers being expendable. The long-term storage tanker(s) would be designed for cryogenic liquid oxygen (LOX), cryogenic liquid hydrogen (LH2), and a variety of storable propellants. In general, all the expendable tankers are used only once for propellant transfer to the LEO Depot. Once the expendable propellant tankers transfer their propellant to the reusable long-term storage tanker they are then disposed of by a reentry maneuver to burn up the tanker in the atmosphere. A long-term goal for this propellant delivery service is to transition to a reusable launch system, as mentioned above, that includes built-in reusable propellant tanks.



Figure 3. LEO Depot. A LEO Depot is shown based on ISS heritage hardware consisting of a truss section with docking ports, solar arrays, radiators, sunshield protecting a propellant storage tank, and a pressurized node module. Attached vehicles include a Reusable Upper Stage, reusable Crew Transfer Vehicle, and a Crew Return Vehicle. 
The CTV has a dry-mass of $\sim 15,200 \mathrm{~kg}$. A mass budget was calculated to include a 6,000 kg propulsion system, $4,200 \mathrm{~kg}$ for the human systems including crew cabin and servicing equipment, and 5,000 kg for the aerocapture system including a nose cap and tail flare. Figure 4 illustrates the conceptual layout envisioned for the CTV. Since it is designed for aerocapture maneuvers, when in its closed configuration, it can be launched on an ELV without a payload fairing. The crew cabin can vary in size from that shown, and the docking port arrangement can be in the nose and/or the topside payload bay area. Both are shown in Figure 4 to illustrate the flexibility available with this configuration. The forward docking mechanism is exposed when the spherical heat shield is opened up, which facilitates docking maneuvers at the depot and facilitates multiple vehicle configurations for future deep space missions out of the L1 Depot. Large forward facing windows with sunshields are also illustrated. On the topside with the payload bay doors open is a docking port that is sized to match an ISS payload hatch. This configuration would allow the transfer of large ISS rack-sized payloads in an out of the CTV for transfer to other destinations at L1 as the infrastructure grows. Behind the crew cab is a human Free Flyer ${ }^{4}$ vehicle docked to a port for use in servicing other vehicles in space. This is an option proposed in lieu of, or in addition to, traditional EVA as done from the ISS. The color-coding on the sides of the CTV indicates the approximant sizes of the large LH2 tank and smaller LOX tank supplying a reusable propulsion system at the aft end. Propellant transfer mechanisms to resupply these tanks with cryogenic propellants are not shown, and are a point for further research and development of this design. Conceptually, propellant transfer could be done through feed lines at the forward docking port, separate feed lines between the LH2 and LOX tanks, or a separate docking port at the aft end. These options will need further trades for safety and on-orbit operations considerations.

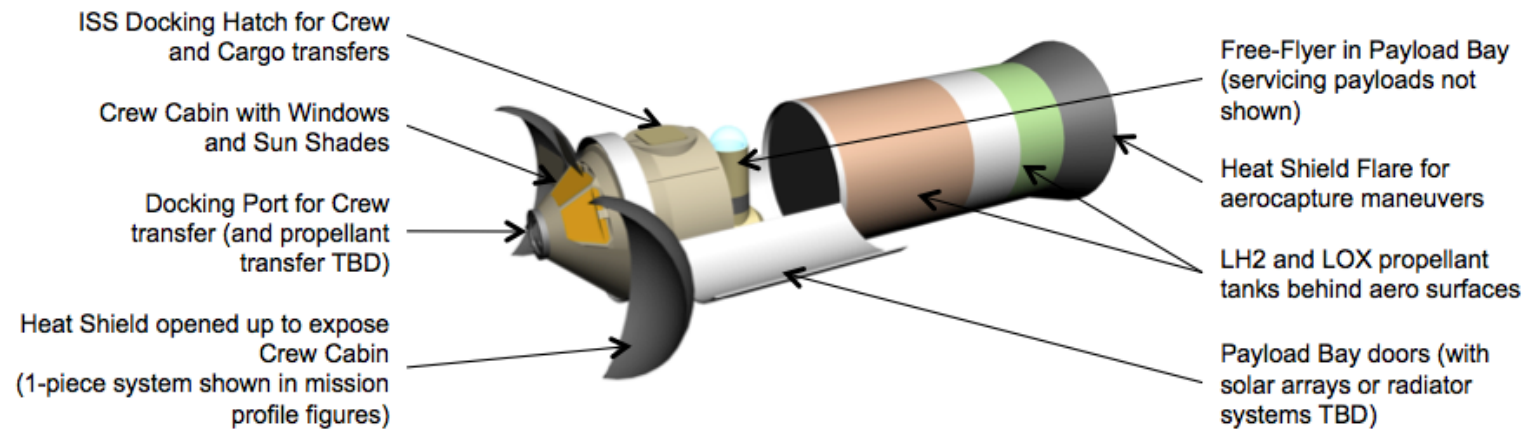

Figure 4. Crew Transfer Vehicle. This configuration for the reusable Crew Transfer Vehicle shows a crew cabin and docking mechanism in the nose behind an open spherical heat shield, the remainder of the crew cabin behind payload bay doors, and an open bay for payloads that includes a human Free-Flyer servicing vehicle.

\section{B. L1 Infrastructure Buildup}

The L1 Depot is the hub for exploration missions and expanded commercial development beyond LEO. It supports reusable vehicles that can deliver crews and cargo to the surface of the Moon, servicing operations for future systems at ESL2, exploration of near-Earth-asteroids, and missions to Mars. The L1 Depot is similar to the LEO Depot and is set in place with five hardware launches plus crew launches as required. Figure 5 provides a graphic representation of the required launches and mission profile. The L1 Depot mass of $\sim 43.5 \mathrm{mt}$ is divided into five launches directly to L1 of 9 to $10 \mathrm{mt}$ each. An alternative to this approach, discussed later for the Mars Orbital Depot, is to deliver the hardware through the LEO Depot utilizing two RUS vehicles. More options like this will become apparent as the infrastructure grows.

Figure 5 also indicates that two flights to the LEO Depot can deliver a reusable Lunar Lander and the propellant required for the Lander to fly itself from LEO to the L1 Depot. If crew assembly is required then two to three additional flights are required to launch the crew and propellants to the LEO Depot and then transfer both into the CTV for a roundtrip flight to L1 and back. The L1 Depot is important for access to all destinations in deep space, which is why L1 is sometimes referred to as a "gateway" or part of a "highway" in space. Transfers from L1 to the Moon, Mars, ESL2, and back to LEO can be timed and coordinated to minimize propellant requirements. This is not true for a low-lunar-orbit (LLO) depot where coordination of efficient launch windows between LLO and the ISS or a LEO Depot can be problematic. 


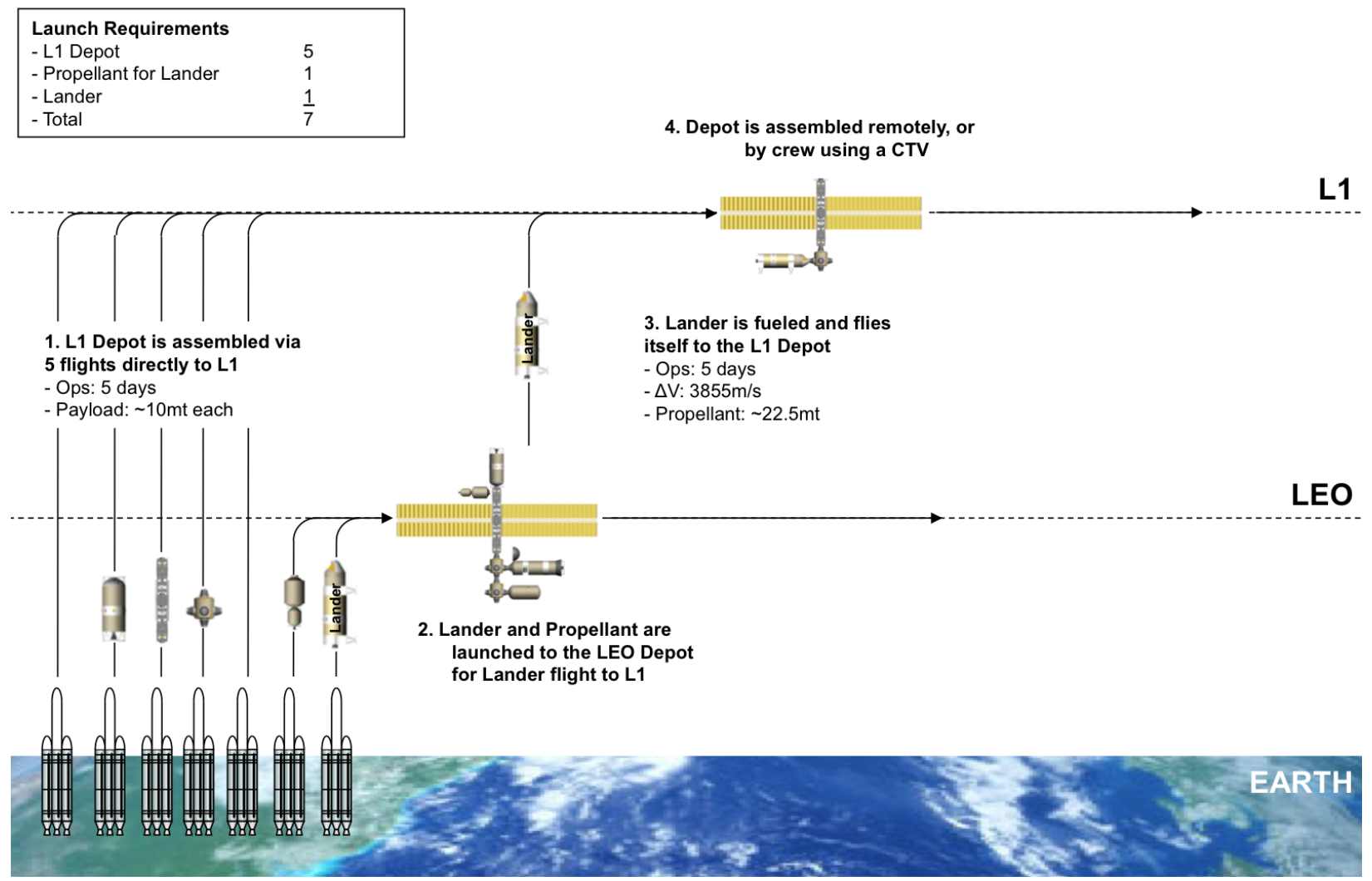

Figure 5. L1 Depot. The L1 Depot configuration is similar to the LEO Depot. Five launches directly to L1 are required for depot hardware deliver, and two launches to the LEO Depot for the reusable Lander and its' propellant. The Lander once fueled can fly itself from the LEO Depot to the L1 Depot.

Once the L1 Depot is in place with the reusable Lunar Lander then lunar surface exploration can begin. Figure 6 provides a graphic representation of how a typical lunar mission could be done using the CTV between the LEO and L1 Depots and the Lunar Lander stationed at L1. Appendix A-2 provides a reference profile for CTV transfer from LEO to L1 and Appendix A-3 provides a reference profile for the Lunar Lander transfer from the L1 Depot to the lunar surface and back to L1. Four propellant launches sent directly to L1 deliver $\sim 8.7 \mathrm{mt}$ of propellant each to the L1 Depot to supply the Lander with the $\sim 30 \mathrm{mt}$ of propellant required for each mission. Three additional flights support crew and logistics delivery to the CTV stationed at the LEO Depot for its round trip flight to the L1 Depot and back. Note that the CTV transfer to L1 does not require an RUS stage as required for the GEO mission. That is because the $\Delta v$ for transfer to L1 is less than that required for access to GEO. Each lunar mission requires seven launches; six are for propellant delivery to support the reusable Lander and reusable CTV, plus one launch of the CRV with the crew. The propellant tankers delivered to L1 are expendable and so each includes enough propellant for self-disposal into the far side of the Moon. As mentioned for the LEO infrastructure, future goals include more reusability in this part of the infrastructure as well, which could include future solar electric propulsion (SEP) systems.

The reusable Crew Lander is illustrated in Figure 7. It is in a horizontal configuration with the crew cab at the forward end, cryogenic propellant tanks in the center, and two de-orbit engines in the aft end. Storable propellants with horizontal landing engines are concealed behind each of the four landing legs for horizontal landing and liftoff from the surface of the Moon. There is no separate ascent stage because the entire vehicle is reusable. Lander dry mass is $\sim 12 \mathrm{mt}$ including $\sim 800 \mathrm{~kg}$ of payload capacity. This configuration, shown in its deployed configuration, is designed for launch on a $5 \mathrm{~m}$ diameter ELV like the Delta IV Heavy or a future Falcon Heavy.

Figure 8 illustrates how a reusable Cargo Lander could be derived from the Crew Lander configuration. Two Landers without crew cabs are assembled on-orbit with a payload support structure attached between. In this configuration, a $\sim 10 \mathrm{mt}$ payload could be delivered to the lunar surface with no expendable components. Propellant requirements would be about twice that of the Crew Lander requiring approximately eight propellant flights to fill the Cargo Lander plus payload and crew support flights as needed for each cargo mission. 


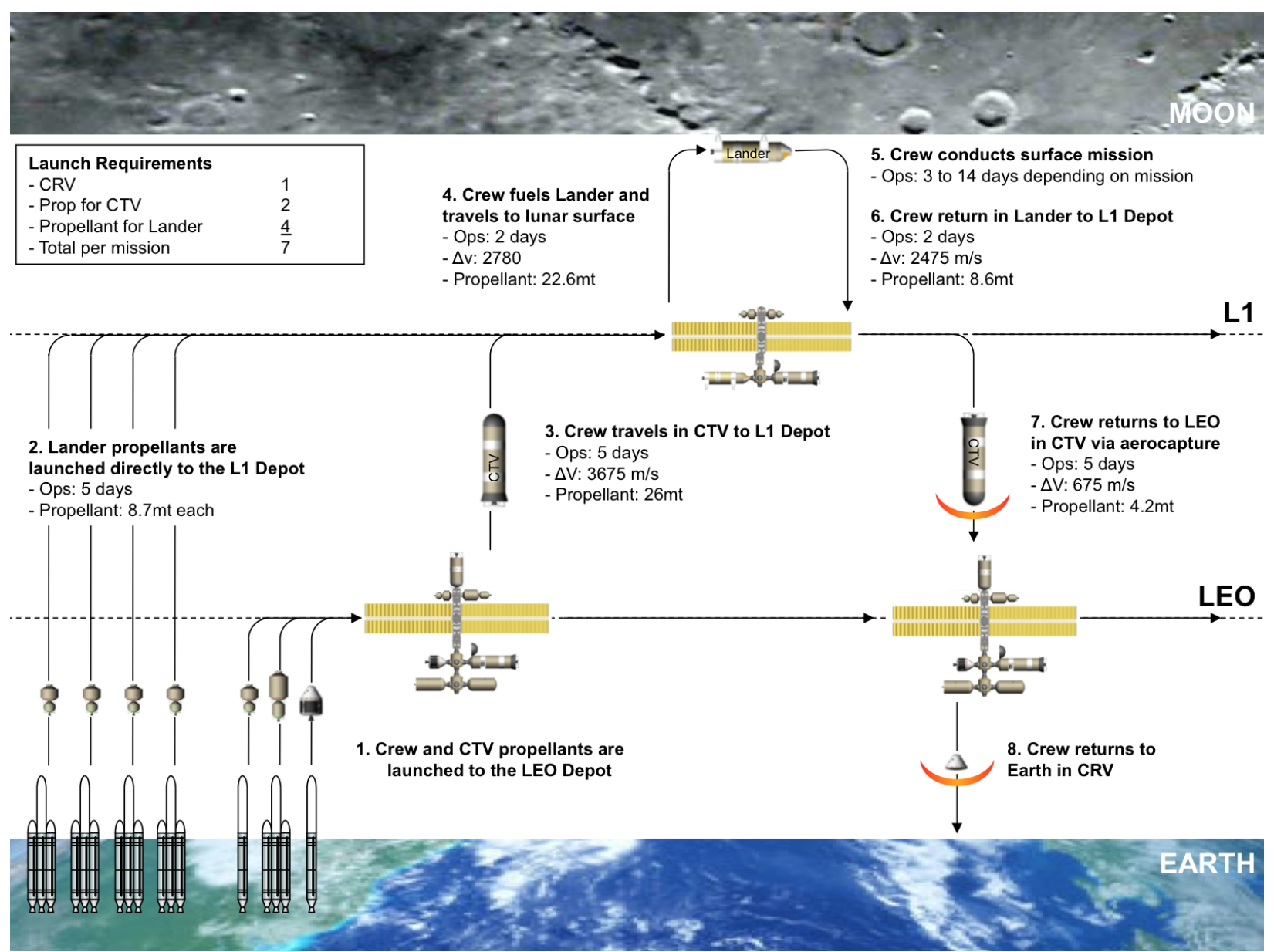

Figure 6. Lunar Missions. With a LEO Depot, a L1 Depot, a reusable Crew Transfer Vehicle, and a reusable Lunar Lander, human missions can be done as needed to the surface of the Moon with 6 propellant launches and 1 crew launch per mission. See Appendix A-2 for the CTV and Appendix A-3 for the Lunar Lander Reference Profile details.

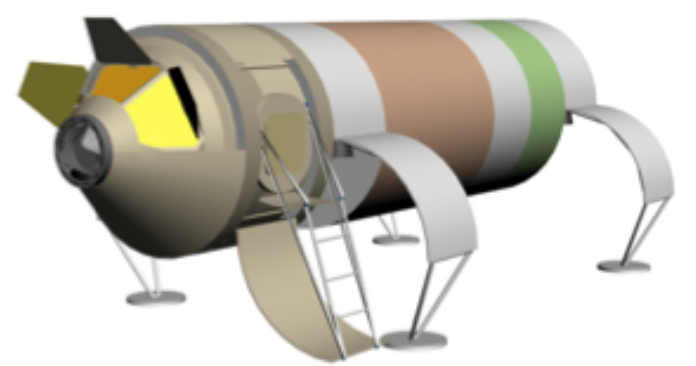

Figure 7. Lunar Lander. This configuration for a reusable Lunar Lander shows a crew cabin at the forward end with four landing engines behind each of the four deployed landing legs. Two orbital transfer and descent engines are located at the aft end.

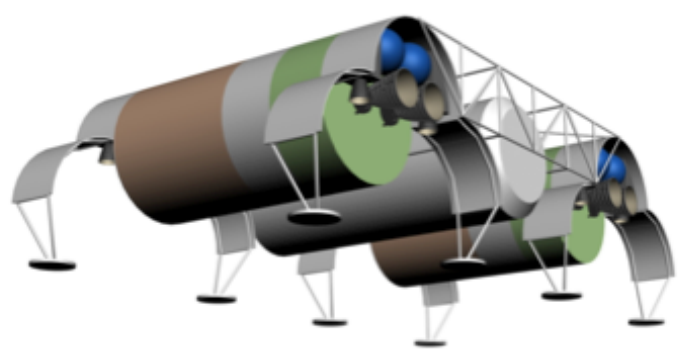

Figure 8. Cargo Lander. This configuration for a reusable Cargo Lander utilizes two standard crew Landers without the crew cabin at the forward end. The payload is suspended from a truss structure between the two vehicles. 
As the traffic grows at both the LEO and L1 depots, additional habitation and cargo handling capabilities will be needed. Figure 9 provides a graphic representation of the delivery of a DSH to the L1 Depot using a RUS with aerocapture capabilities. Three launches are required for each $\sim 16.2 \mathrm{mt}$ cargo delivered through the LEO Depot to the L1 Depot. This would include one cargo flight, in this case a DSH, and two propellant flights to supply the RUS. The previous RUS shown if Figure 2 provided an initial boost of the CTV for GEO servicing and did not have a high enough velocity on return to require an aerocapture system. However, for RUS deliveries all the way to L1 the return velocity is similar to that of the CTV, so a similar aerocapture system is utilized.

Appendix A-4 provides a reference profile for payload delivery from the LEO Depot to the L1 Depot using two RUS vehicles. It indicates that a first stage $4.3 \mathrm{mt}$ RUS plus a second stage $8.8 \mathrm{mt}$ RUS with an aerocapture system requires $\sim 62 \mathrm{mt}$ of propellant to deliver up to $\sim 33.5 \mathrm{mt}$ payloads from the LEO Depot to the L1 Depot. This is the type of vehicle configuration that might be best utilized for construction of the L1 Depot as mentioned previously, and for delivery of a larger DSH for the Mars missions discussed later in this paper.

Comparisons were also made at this stage for CTV transfers from the ISS to the L1 Depot and return to the ISS. These were found to have similar propellant requirements indicating that the ISS could also be utilized as part of this space transportation infrastructure. ISS utilization may be preferable for some international participation using high latitude launch sites. With the DSH in place at the L1 Depot it is possible to consider crew missions to ESL2 and near Earth asteroids.

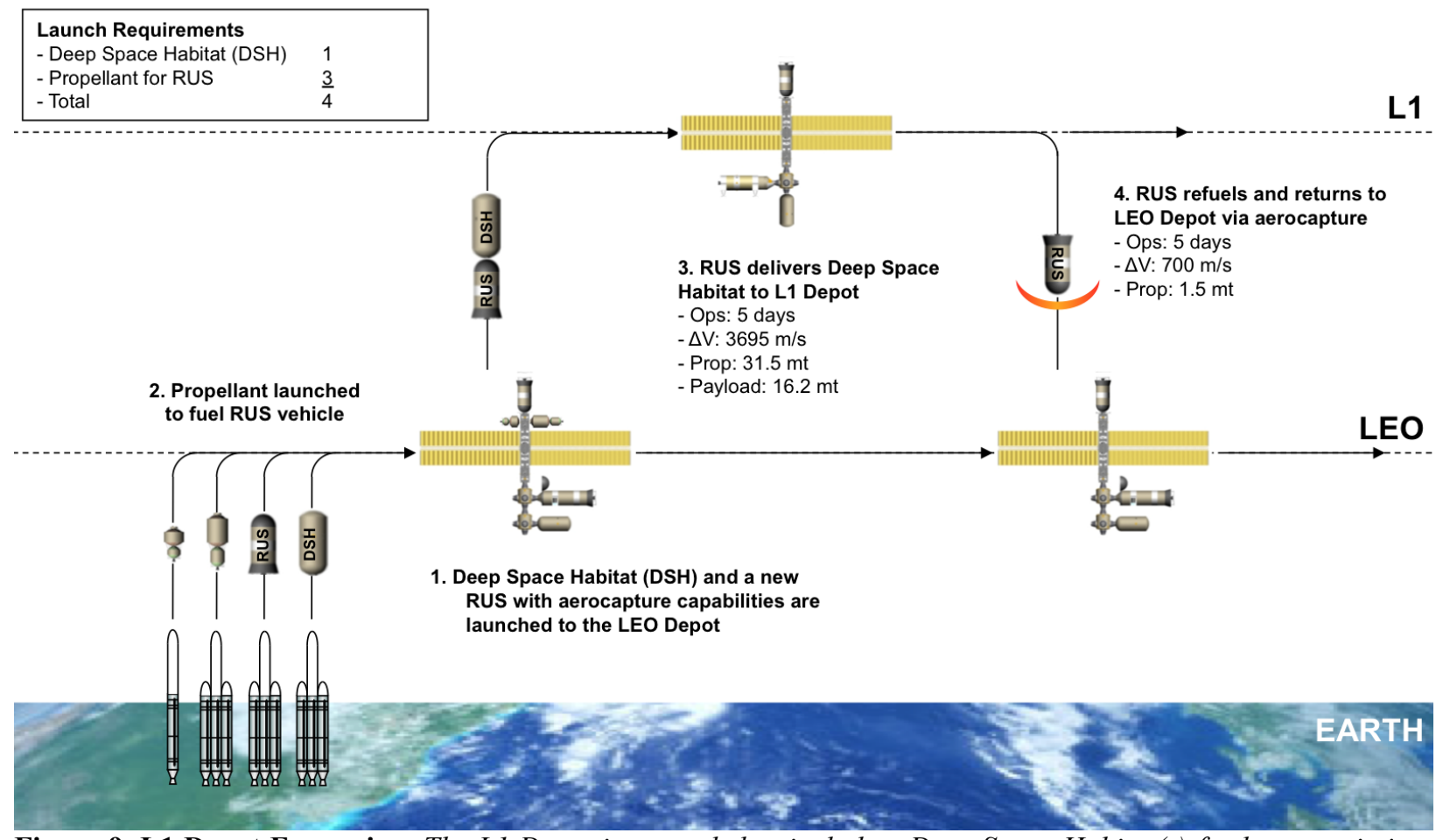

Figure 9. L1 Depot Expansion. The L1 Depot is expanded to include a Deep Space Habitat(s) for human missions to ESL2, near Earth asteroids, and Mars missions. A reusable upper stage with aerocapture capabilities is also added for cargo deliveries to L1.

Figure 10 provides a graphic representation of how ESL2 missions could operate out of the L1 Depot, and Appendix A-5 provides a reference profile for the assumed vehicle masses and propellant calculations. Each mission would require on-orbit assembly at the L1 Depot of a RUS, CTV, and DSH. Total propellant requirements for the RUS and CTV would be $\sim 27 \mathrm{mt}$ each, or $\sim 54 \mathrm{mt}$ total delivered directly to the L1 Depot in six launches. Including crew would add three more launches for a total of nine launches per ESL2 mission. The RUS would be similar in design to the RUS used for GEO missions because it would not require an aerocapture system. It would act as a boost stage to deliver the CTV and DSH to ESL2 and would then return to the L1 Depot. The CTV is utilized primarily for return propulsion to return the DSH to the L1 Depot. It includes the standard aerocapture system used for the L1 to LEO transfer so it could also deliver the crew directly to the LEO Depot in the event of an emergency. The CTV includes all the features described for the GEO servicing mission so it can perform servicing at ESL2 destinations. The DSH upon return to the L1 Depot is serviced and resupplied for the next mission. 


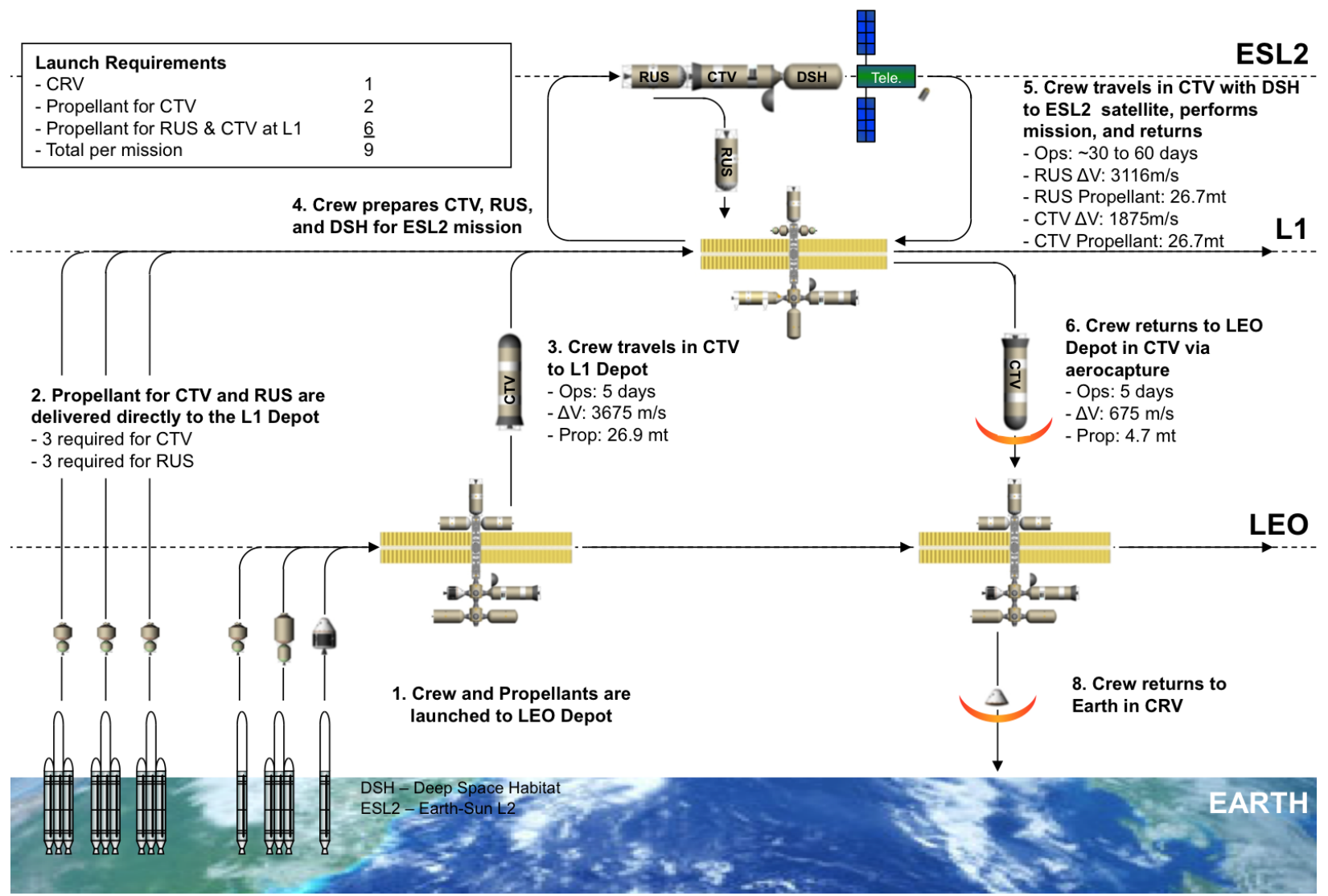

Figure 10. ESL2 Missions. A human servicing mission to an Earth-Sun L2 destination would take 30 to 60 days and requires a RUS, CTV, and DSH operating out of the L1 Depot. One crew launch and eight propellant launches for a total of nine launches per mission would be required. See Appendix A-5 for ESL2 Mission Reference Profile details.

Several DSH sizes were calculated for various crew sizes and mission durations. For the purposes of this exercise, two module sizes were selected similar to the layout shown in Figure 11. The smaller module, $\sim 16.2 \mathrm{mt}$, with differing logistics and equipment loads was considered reasonable for ESL2 missions and some near Earth asteroid missions. A larger module or double module design was assumed for Mars orbital missions at $\sim 33.5 \mathrm{mt}$ not including aerocapture systems. The habitation module shown in Figure 11 is based on ISS module technology and is about the length of a combined ISS Lab and Node. Docking ports are located at each end with one end subdivided with an internal bulkhead that can accommodate an internal airlock and side docking ports. For some asteroid missions and all Mars missions an aerocapture system is added that includes a spherical nose cone and tail flare such that its appearance is very similar to the CTV. Delivery of the larger DSH to the L1 Depot would be similar to the approach shown in Figure 9, but would utilize two RUS vehicles to push the additional mass as described in Appendix A-4.

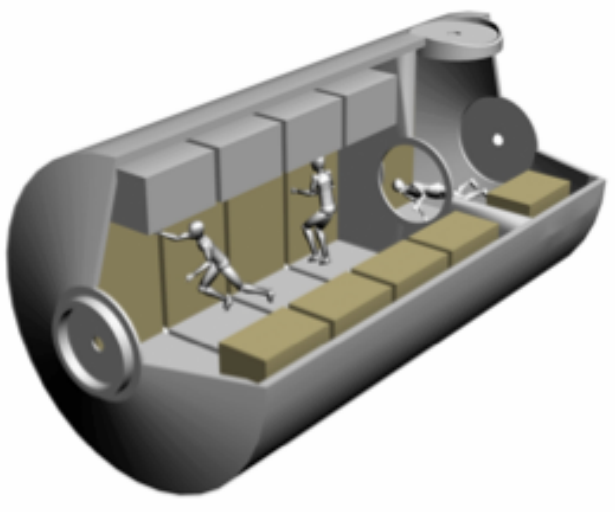

Figure 11. Deep Space Habitat Cut-Away View. This configuration for a Deep Space Habitat is about the size of the ISS Lab and Node modules combined. It includes ISS type racks, an internal airlock, and docking ports at each end and on the sides at the airlock location. 
Asteroid missions operate out of the L1 Depot using the CTV, DSH, and in most cases an RUS or several reusable and/or expendable propulsion stages depending on the difficulty of the asteroid mission. Figure 12 provides a graphic representation of a mission to asteroid $2009 \mathrm{HC}$ requiring the CTV, DSH, and one attached RUS. In this case $\sim 61 \mathrm{mt}$ of propellant would be required for the CTV and RUS. This would require 7 propellant launches directly to the L1 Depot plus 3 launches for crew and propellants delivered through the LEO Depot to the L1 Depot for a total of 10 launches to support this mission.

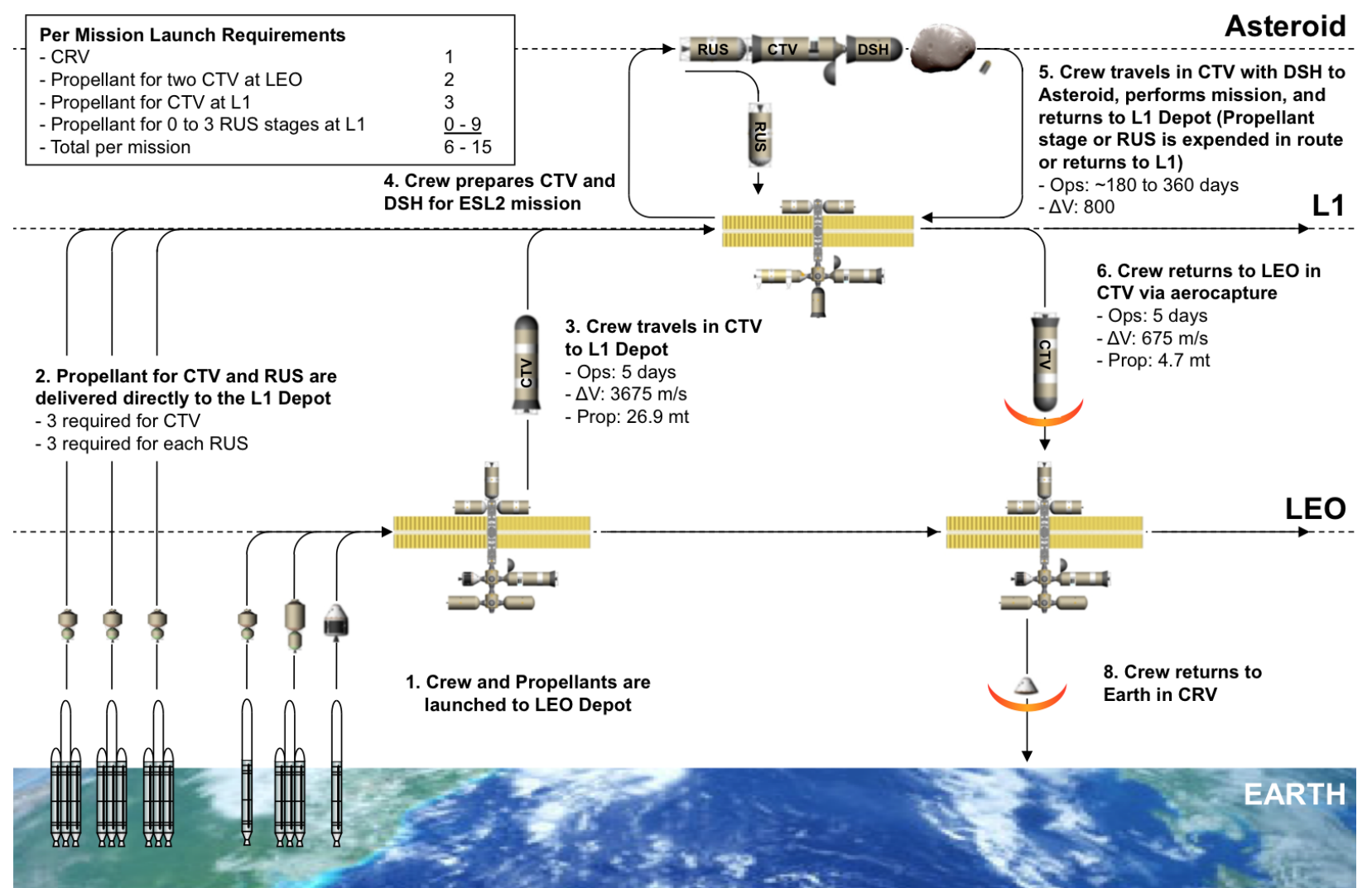

Figure 12. Asteroid Missions. The launch requirements for the asteroid missions analyzed varied from 6 to 15 launches per mission including propellant and crew. In some scenarios all elements are reusable and in others only the CTV and DSH are reusable.

Figure 13 provides a graphic representation of the $2009 \mathrm{HC}$ mission and three others analyzed utilizing the L1 Depot infrastructure. The simplest mission was to Asteroid 2000 SG244, which required the CTV and DSH with no attached RUS vehicles. Only five propellant launches and one crew launch were required for a total of six launches. The most difficult mission analyzed was to Asteroid 2001 QJ142, which required three attached RUS vehicles. This mission required at least fourteen propellant launches, and one crew launch, for a total of fifteen launches. Note that in each case all the in-space elements are designed for reusability. Also, the CTV flight from LEO to L1 and back is the same as in previously described missions using the reference profile provided in Appendix A- 2 .

Figures 1 and 13 provide a schematic of the orbital paths envisioned for all these missions. They do not represent actual trajectories, but there are some important notional features. In most cases, any transfer to and from the L1 Depot includes a flight path around the Earth and Moon using powered gravity assist as needed to help decrease the total delta-V required. For example; the transfer from the LEO Depot to the L1 Depot uses a trajectory from LEO around the Moon and back to L1; the asteroid and Mars missions from the L1 Depot would likely include a trajectory from L1 around the Moon and the Earth out to their destinations; and the return trajectories would likely be reversed with each coming in around the Earth and the Moon and then back to the L1 Depot. Many of the Figures provide operations times in days which took these trajectories into consideration and were thus helpful in sizing the crew systems for the various vehicle configurations. 


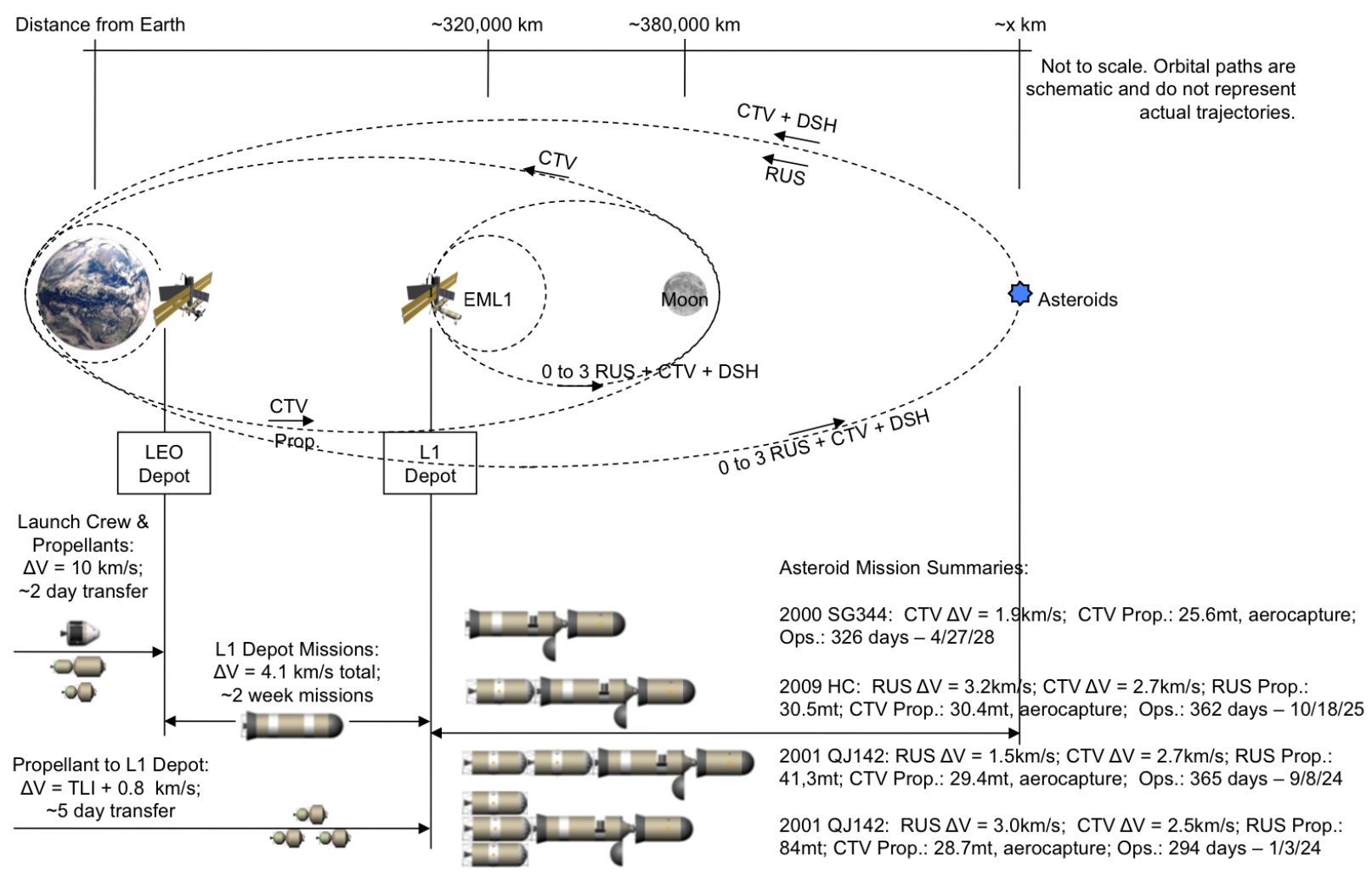

Figure 13. Asteroid Missions. Asteroid mission vehicle requirements can vary from mission to mission. In these examples it can be seen that the simplest mission requires only a CTV and DSH, whereas the most difficult example requires the CTV, DSH, and 3 attached RUS vehicles.

\section{Mars Infrastructure}

Mars missions operate out of the L1 Depot using the CTV, DSH, and RUS for crew and payload delivery to a Mars Orbital Depot (MOD). The MOD is placed in a 24-hour polar orbit to support all missions to the surface of Mars for both crew and cargo delivery with a system designed to eventually draw on Mars surface resources for propellant production. The intent is to eventually build up the same type of highly reusable in-space systems at Mars as described within the Earth-Moon system using the LEO and L1 depots.

Cargo launches from the L1 Depot to the MOD are not as difficult as some of the Asteroid missions and can vary in size depending on the payload requirements. Figure 14 provides a graphic representation of the initial MOD delivery to Mars orbit, and Appendix A-6 provides a reference profile for a cargo transfer from the L1 Depot to Mars orbit for a 47 mt MOD payload. Figure 14 illustrates one example of how the MOD might be put in place. It uses two payload launches to the LEO Depot of $\sim 20 \mathrm{mt}$ each to deliver a $\sim 40 \mathrm{mt}$ depot to orbit similar in design to the LEO and L1 depots. Three additional propellant flights are used to supply 2 RUS vehicles to boost the payloads up to the L1 Depot. Note that neither of the RUS vehicles have an aerocapture system so their performance capability is little higher than the $\sim 33.5 \mathrm{mt}$ capability described in Appendix A-4. Options for reuse of these RUS vehicles includes refueling them at L1 for utilization in other missions beyond L1 or returning them to the LEO Depot using propulsive capture in lieu of aerocapture into LEO. At L1 the entire Mars Cargo vehicle is assembled including the MOD payload and 2 RUS vehicles. Six propellant launches directly to the L1 Depot are required to supply the two RUS vehicles. One RUS is used for Trans-Mars Injection (TMI) and a second RUS is used for propulsive capture to deliver the MOD payload into Mars orbit. Total launch requirements included 11 propellant launches, 2 payload launches, and 1 crew launch for a total of 14 launches to deliver the MOD payload through the LEO and L1 depots to Mars orbit. The crew flight is included under the assumption that their assistance will be required to assemble the payloads at the LEO Depot for transfer to L1 and then assist with final assembly of the Mars Cargo vehicle at the L1 Depot for its flight to Mars orbit. Similar analysis and reference profiles were generated for delivery of Trans-Earth Injection (TEI) stages, Mars Landers, propellants for reusable Landers, 
additional Deep Space Habitats and other orbital and surface assets. In some cases, Cargo vehicles with aerocapture capabilities were utilized that were similar to the CTV in size and configuration. The finding was that there are a variety of configurations that this infrastructure can accommodate to optimize delivery capabilities of many different payload masses and configurations through the LEO and L1 depots to the Mars Orbit Depot.

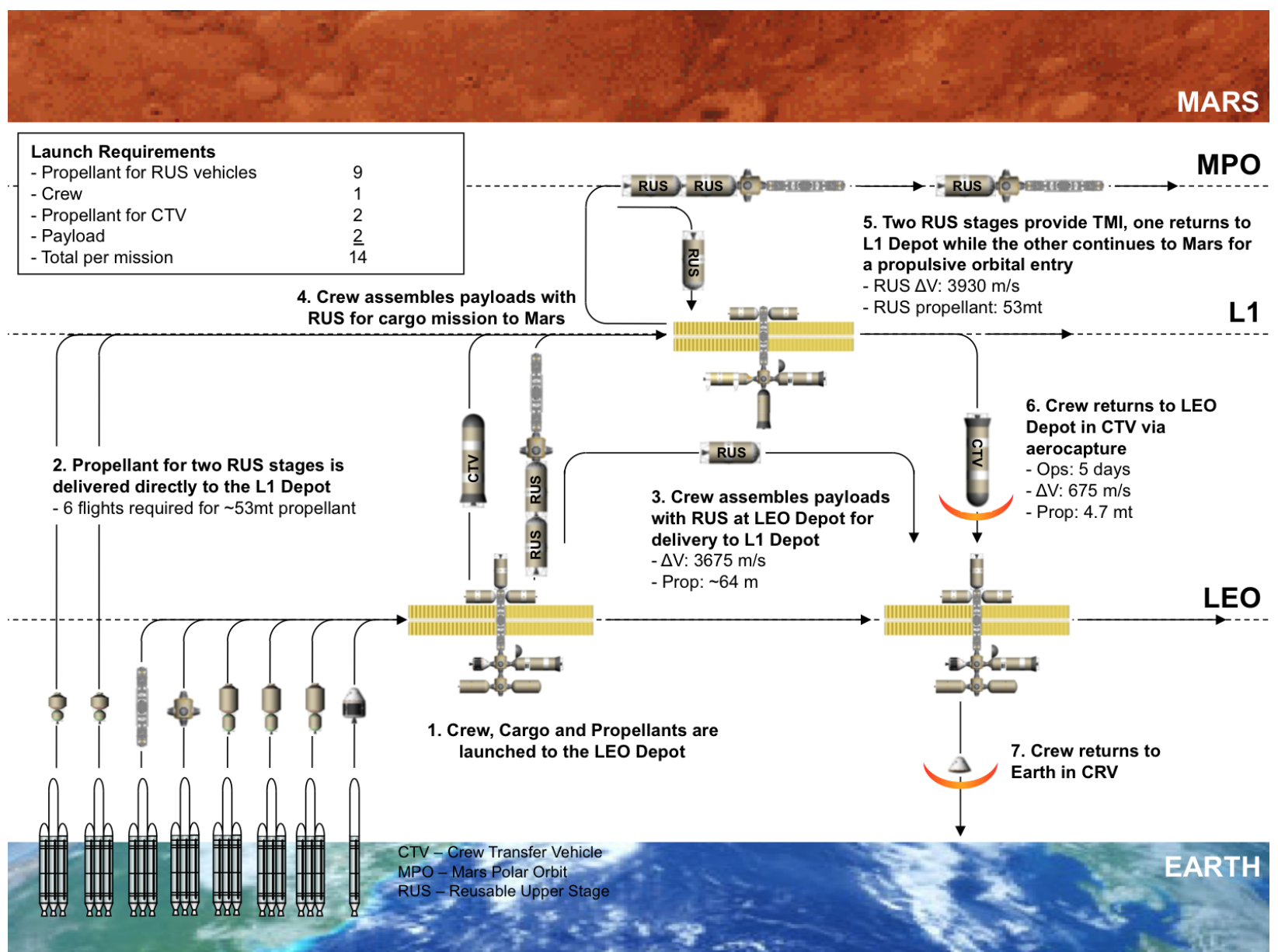

Figure 14. Mars Orbital Depot Delivery. The Mars Orbital Depot would require about 14 launches to deliver $\sim 40 \mathrm{mt}$ to the L1 Depot for transfer to Mars orbit. Appendix A-6 provides a reference profile for delivery of the Mars Orbit Depot from the L1 Depot to Mars orbit.

The initial crew missions will be more complicated than cargo missions due to the additional mass required for crew return. It is assumed in this scenario that a crew will be required for assembly, deployment, and initial operations of the MOD. This would likely be a $\sim 500$ day short stay mission with $\sim 30$ days in Mars orbit to assemble the MOD and perhaps deploy remotely controlled robotic explorers on the surface of Mars and the two Martian moons. Figure 15 provides a graphic representation of a crew mission to Mars orbit during the early stages of the Mars infrastructure development, and Appendix A-7 provides a reference profile showing assumed vehicle and payload masses, and propellant calculations. The crew travels in a CTV with an attached DSH and 4 RUS vehicles. The RUS vehicles are reusable and eventually return to the L1 Depot. They carry $\sim 30 \mathrm{mt}$ of propellant each plus an additional $\sim 36 \mathrm{mt}$ in the CTV and DSH for $\sim 156 \mathrm{mt}$ total for the mission. Hardware includes the standard RUS and CTV elements plus a DSH that is outfitted for a longer mission at $\sim 33.5 \mathrm{mt}$ plus an additional $\sim 6 \mathrm{mt}$ for propulsion and aerocapture systems. At this early stage of Mars development, 21 launches are required to deliver the crew and propellants through the LEO and L1 depots for each crew mission to the MOD. This does not include delivery of the reusable hardware, much of which has been delivered as part of other ongoing missions. 


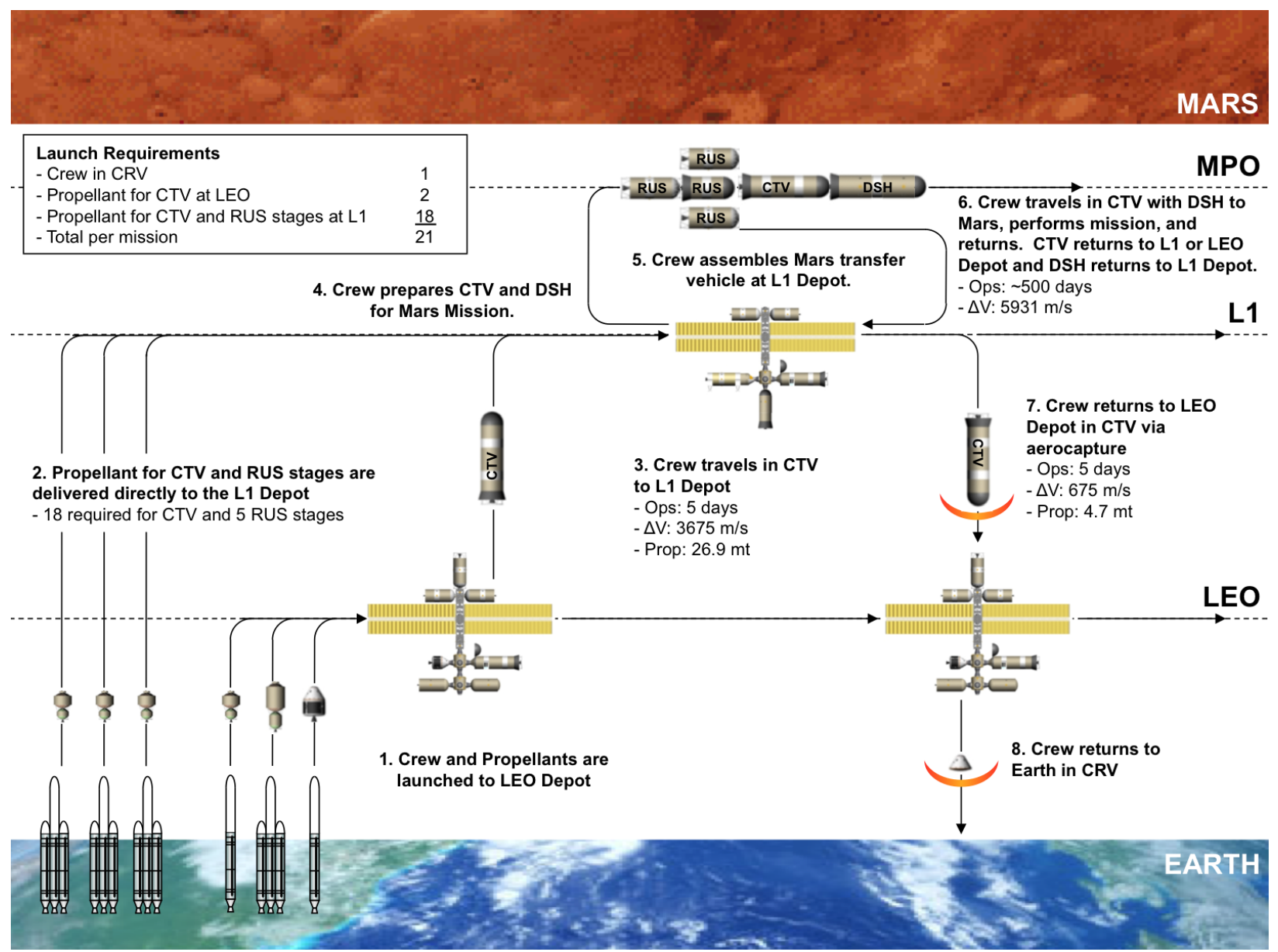

Figure 15. Mars Crew Missions. A typical crew mission to Mars during the early phases of development will require a CTV, DSH, and 4 RUS vehicles. See Appendix A-7 for a typical Crew Mission Profile to Mars orbit.

At Mars orbit the RUS, CTV and DSH will separate from each other and enter Mars orbit independently via an aerocapture maneuver. Three RUS vehicles are used for TMI and return to the L1 Depot and the fourth continues to Mars orbit for use as a TEI stage for the return trip. Figure 16 provides a graphic representation indicating that the vehicle will arrive in Mars orbit with the CTV, DSH, and one attached RUS. The three vehicles will separate and enter an aerocapture trajectory for rendezvous with the MOD. The crew will travel in the CTV to the MOD where there will be a prepositioned DSH for contingency accommodations. Also, prior to separation the crew will have the option of bypassing Mars for return to Earth using the DSH with the CTV and attached RUS propellants. Future missions might have a pre-positioned RUS for crew return, and might further optimize the vehicle capabilities by using in-situ resources from Mars for propellant production.

For ongoing operations to Mars the crew missions will become similar in scale to the Cargo missions through use of a DSH in a semi-cycler orbit. Figure 17 illustrates the concept where a replacement crew departs the DSH as it approaches Mars and transfers in their CTV to the MOD while the previous crew transfers in their CTV from the MOD to the DSH as it passes by. Appendix A-8 provides a reference profile for this approach using a CTV, DSH, and three RUS boosters. The RUS boosters provide for TMI from the L1 Depot and return to L1. The CTV departing L1 along with the DSH provides for the remaining propulsion to the MOD along with the TEI propulsion required for return with the next DSH flyby. The CTV at the MOD provides for the TEI propulsion for return of the previous crew with the DSH as it passes by Mars for return to the L1 Depot, thus completing the semi-cycler transfer system. Propellant requirements are equivalent to three RUS vehicles plus the DSH and CTV, or $\sim 127 \mathrm{mt}$. So, each semi-cycler crew mission would require $\sim 18$ launches for both crew and propellants delivered through the LEO and L1 depots. Additional advancements for the semi-cycler concept are possible once a Mars surface propellant production capability is established. The surface infrastructure is not included in this paper but the MOD infrastructure is designed conceptually to support reusable Mars Landers that are resupplied with propellant produced on the surface of Mars or with deliveries from the Earth-Moon system. The intent is that once the MOD is 
in place then the next task is for the crew to operate out of the MOD with remote systems to set up propellant production on the surface of Mars to support reusable Mars Landers and human and robotic surface exploration systems. The combination of reusable and sustainable surface and orbital assets is envisioned to eventually enable exploration around the entire planet and the establishment of a permanent human presence in orbit and on the surface of Mars.

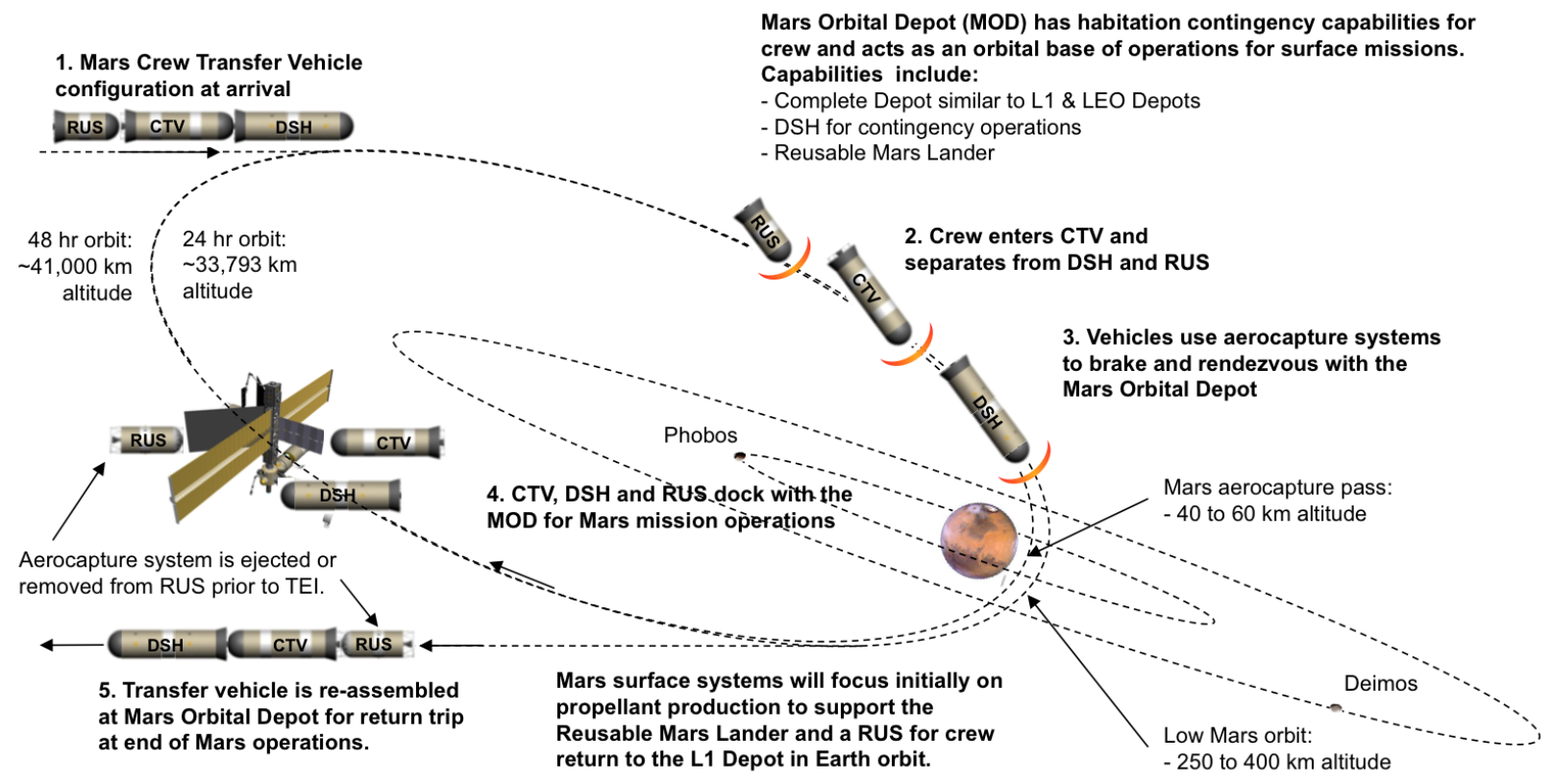

Figure 16. Mars Orbital Depot. A typical crew mission going to the Mars Orbital Depot will consist of a RUS, $C T V$, and DSH. All three elements have an aerocapture capability and will separate and enter Mars orbit independently for rendezvous and docking with the depot. See Appendix A-7 Crew Mission Reference Profile to Mars orbit.

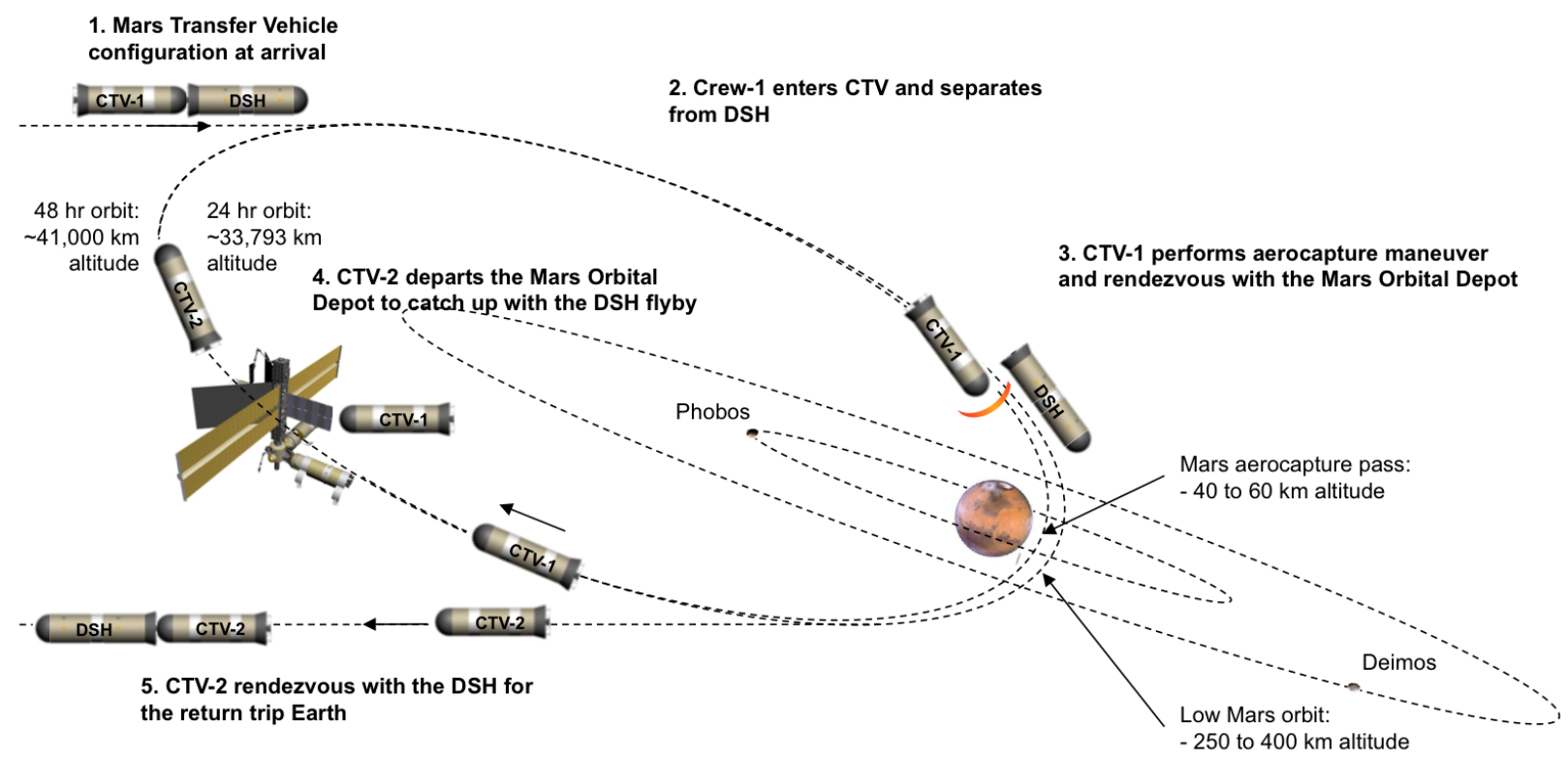

Figure 17. Mars Semi-Cycler. A typical crew mission using a DSH in a Semi-Cycler orbit will have one crew transfer in their CTV to the Mars Orbital Depot while the other crew transfers in their CTV from the Mars Orbital Depot to the DSH as it passes by. Three RUS boosters, not shown, provide the initial TMI capability and the CTV provides the return TEI capability. See Appendix A-8 Semi-Cycler Crew Mission Reference Profile to Mars orbit. 


\section{Affordability}

The development of this space transportation system based on propellant depots can be phased in over time so that the infrastructure can be put in place within constrained budgets. This is an important feature with historic precedence. In examining the NASA budget ${ }^{5 \mathrm{~d}}$ during the Apollo Program it is notable that it grew to $\sim \$ 33 \mathrm{~B}$ during the peak of development in the mid-1960's and then dropped to a third of that amount, $\sim 11 \mathrm{~B}$, by the end of the program in the mid-1970's. The International Space Station program shows no substantial budget peak during its development in the 1990's and 2000's because it was broken into segments and developed and assembled in space incrementally over nearly two decades. The NASA budget grew, but at a steady pace from $\sim \$ 13 \mathrm{~B}$ to $\sim \$ 15 \mathrm{~B}$ during that time period. The apparent problem with the Constellation Program was that two new launch vehicles and all the payloads that would fly on them had to be developed nearly simultaneously similar to the Apollo Program experience causing a peak in a flat budget environment. The depot-based transportation infrastructure described in this paper does not have to be developed all at once to succeed. It can be developed incrementally, starting in LEO, and then expanding to L1, the Moon, and then Mars as time and budgets permit.

The largest part of the recurring cost for the depot-based infrastructure is the propellant launches required to support the reusable in-space vehicles. The propellant and launch vehicles, being the most massive and expensive elements in the infrastructure, can be supported by any commercially available launch vehicle. The attractive features of this delivery approach is that it increases US production of existing launch vehicle systems, it reduces sole source procurements, it promotes competitive bidding, and it generates a higher flight rate which will stimulate a demand for the development of new reusable launch vehicle systems. Another recurring cost that the Apollo Program faced as did the Constellation Program was generated from the lack of reusability. Everything was expendable and had to be reproduced for each mission. Most of the in-space transportation infrastructure proposed in this paper is reusable for many missions because the transportation elements are serviced by the depot infrastructure elements. These features should have a significant long-term impact for reducing space transportation cost, maintaining steady budgets, and making the overall infrastructure safe and affordable.

Another attractive feature of the depot infrastructure is the multi-mission, multi-use capabilities that this transportation system offers. For example, while lunar missions are ongoing using the LEO and L1 Depots it will be possible to plan and execute satellite servicing out of the LEO Depot, and ESL2, Asteroid, and Mars missions out of the L1 Depot. This multi-mission infrastructure approach should realize a significant boost to exploration and commercial missions with significant cost savings over time because multiple government and commercial missions can operate simultaneously. This was a significant problem with the Apollo and Constellation architectures because they were single purpose systems designed for lunar exploration and eventual Mars transportation without any commercial opportunities or simultaneous multi-mission capabilities.

Propellant depots can work well with heavy-lift launch vehicles too when there is a real need for larger payloads with larger propellant requirements. This could be a capability that should be explored further for Mars missions where the reference missions above in Figures 12 and 15 require 14 to 21 Delta IV Heavy launches per mission. Future SEP vehicles can also help with the number of launches by reducing the propellant requirements for transfer of propellant and payloads between LEO and L1, and between L1 and Mars destinations. Small electric thrusters or SEP systems were included in the propellant calculations for all the depot station keeping required for the scenarios described in this paper, but the larger SEP systems for orbit transfer of large payloads were not considered. Another aspect that can result from this infrastructure is in the development of new reusable vehicle technologies. An infrastructure like this that emphasizes the development of reusable in-space vehicles and creates a significant market for a variety of launch vehicles should have a significant impact on the commercial development of reusable launch vehicles too.

The primary developer of this infrastructure is undefined and an overall cost analysis has not been performed for this transportation system. The intent of this study was to stay focused on a technically feasible approach that could then be used by others to explore methods for economic viability. It seems unlikely that NASA could develop this type of infrastructure when the Agency is science, exploration, and technology focused by law and the infrastructure is designed to support both exploration and commercial activities. Also, when cost are applied to all the new reusable systems to be developed, it may be found that NASA cannot afford everything within a reasonable amount of time even though incremental development is part of the plan. It seems unlikely that the commercial sector can afford this kind of development either because it is an inherently large and complex infrastructure with high upfront cost that would be difficult to recoup within a reasonable amount of time. There have been many types of quasigovernment/industry organizations proposed in the past for large space system developments that should probably

\footnotetext{
${ }^{\mathrm{d}}$ Budget numbers are in 2007 dollars
} 
be considered. Some type of new organization that can formulate, manage, and stimulate the development of space is probably needed. International seaport and airport developments might be analogs to consider. For example, the LEO and L1 depots could be considered airports in space, or Orbital Spaceports. The facilities would be developed and maintained through new organizations supported by both government and private investments. Fees and taxes would be levied, standards would be developed, regulations put in place, flight operations established, and new organizations developed to manage the complexities of the overall infrastructure. There may be many other development and organizational models to consider too.

\section{Conclusion}

The propellant depot system described in this paper shows one way our current commercially available ELV infrastructure could provide for over $90 \%$ of the propulsion and propellants required to support simultaneously all of our commercial and exploration mission needs in the foreseeable future. The ability to place such a large percentage of the transportation mass into a competitive contracting environment should have tremendous economic impact by lowering space transportation cost for NASA and new commercial customers. The incremental development, high flight rates, reusability, and the multipurpose/multi-mission characteristics of this propellant depot infrastructure make it worthy of serious consideration as a part of a long-term development plan for human expansion into space. Establishment of a LEO Depot to support satellite servicing and future commercial and exploration missions, and then expanding quickly with the addition of a L1 Depot for exploration and development out to the Moon and then to Mars has great potential to permanently expand human presence beyond LEO.

The LEO Depot can support satellite servicing missions, new commercial enterprises, and human exploration missions beyond LEO through the L1 Depot. A typical GEO satellite servicing mission was found to require 4 Delta IV Heavy launches for crew and propellants utilizing a reusable CTV and RUS based at the LEO Depot. Both these vehicles have a propellant capacity of $\sim 32 \mathrm{mt}$ and are similar in design with the CTV having an added crew module and payload bay.

The L1 Depot supports all missions beyond the Earth-Moon L1 orbit including the Moon, ESL2, Asteroids, and Mars. The system utilizes the same CTV and RUS, and adds a Lunar Lander and a DSH. The Lunar Lander also utilized a $\sim 32 \mathrm{mt}$ propellant capacity and has many similarities to the size and design of the CTV and RUS. This type of commonality was a goal throughout the depot infrastructure development. A typical lunar mission was found to require 7 Delta IV Heavy launches, ESL2 missions required 9 launches, asteroid missions varied from 6 to 15 launches, and Mars missions varied from 14 to 21 launches once the depots and reusable in-space transportation elements were in place.

This reusable depot infrastructure should promote a robust market for existing commercial launch vehicles and new commercial services in space. Technology development by NASA focused on reusability and reliability in all the in-space systems for depots, transfer vehicles, Landers, and habitats has the potential to open up the space frontier to multiple human space operations conducted simultaneously within NASA and with commercial developers and international partners. NASA's development of reusable technologies for in-space systems will further stimulate the commercial market for development of the next generation of reusable launch vehicles. To accomplish this type of infrastructure NASA and the commercial sector may need to find new organizational structures because neither appears to have the resources or the mandate to do it alone. Continued analysis of this approach, defining organizational responsibilities for its development, and integrating complex cost modeling to analyze the many options, are the next steps needed to move forward with this propellant depot-based space transportation infrastructure. 


\section{Appendix A}

\section{Reference Profiles}

The following reference profile tables are summary calculations from numerous Excel spreadsheets showing the propellant requirements at each stage of the mission based on delta- $\mathrm{V}$, engine Isp, and vehicle mass. The calculations, data sheets, and overall mission profiles have been reviewed numerous times, but due to the complexity of the interrelationships, errors are possible. The authors found that minor changes in assumptions could sometimes have significant impact on the infrastructure, but that in general solutions were always found to optimize the system to the standard vehicles sizes defined. In addition it was found that the overall system is quite flexible, and that multiple vehicle configurations and mission profiles were possible for the more complex missions.

\begin{tabular}{|c|c|c|c|c|c|c|}
\hline Event & Delta V & Isp & Mass Ratio & Propellant & Hardware & Mass Remaining \\
\hline CTV + RUS & & & & 64741.5 & 19228 & \\
\hline Refuel & & & & 64741.5 & & 83970 \\
\hline Boost Phase & 1950 & 455 & 1.548 & 29728.8 & & 54240.8 \\
\hline Separate Booster & & & & 2411.8 & 4300.0 & 47529.0 \\
\hline GTO Ins & 556.00 & 455 & 1.133 & 9837.6 & & 37691.5 \\
\hline GEO Ins & 1783 & 455 & 1.491 & 12415.9 & & 25275.6 \\
\hline Rend/Dock & 25 & 310 & 1.008 & 308.7 & & 24966.9 \\
\hline LEO Return Insertion & 1783 & 455 & 1.491 & 8326.0 & & 16640.9 \\
\hline Post-Aero & 200 & 310 & 1.068 & 1589.7 & & 15051.3 \\
\hline Rend/Dock & 25 & 310 & 1.008 & 123.3 & & 14928.0 \\
\hline Servicing Equipment & & & & & 500 & 14428.0 \\
\hline Propulsion Stage & & & & & 4300 & 10128.0 \\
\hline Nose Cap & & & & & 1000 & 9128.0 \\
\hline TPS & & & & & 2928 & 6200.0 \\
\hline Tail Flare & & & & & 1000 & 5200.0 \\
\hline Crew Cabin w/ Crew of 3 & & & & & 5200.00 & 0.0 \\
\hline Main vehicle propellant & & & & 32601 & & \\
\hline \multirow[t]{2}{*}{ Booster Propellant } & & & & 32141 & & \\
\hline & & & & 2411.8 & & 6711.8 \\
\hline Recover Booster to LEO & 1950 & 455 & 1.548 & 2376.2 & & 4336 \\
\hline Rend/Dock & 25 & 310 & 1.008 & 35.5 & & 4300.0 \\
\hline Booster Empty & & & & & 4300 & 0.0 \\
\hline
\end{tabular}

A-1. GEO Satellite Servicing Reference Profile. See Figure 2 for a typical GEO satellite servicing mission using a Reusable Upper Stage and a Crew Transfer Vehicle. This profile uses one RUS as a booster for the CTV to reach GEO.

\begin{tabular}{|c|c|c|c|c|c|c|}
\hline Event & Delta V & Isp & Mass Ratio & Propellant & Hardware & Mass Remaining \\
\hline CTV & & & & & 16528 & \\
\hline Refuel & & & & 31255.9 & & 47784 \\
\hline TLI & 3200.00 & 455 & 2.049 & 24458.9 & & 23325 \\
\hline L1 Insert (Lunar Enc) & 450 & 455 & 1.106 & 2237.6 & & 21087 \\
\hline Rend/Dock & 25 & 310 & 1.008 & 191.0 & & 20896 \\
\hline LEO Return Insertion & 450 & 310 & 1.160 & 2901.4 & & 17995 \\
\hline Post-Aero & 200 & 310 & 1.068 & 1330.5 & & 16664 \\
\hline Rend/Dock & 25 & 310 & 1.008 & 136.5 & & 16528 \\
\hline Payload & & & & & 2000 & 14528 \\
\hline Propulsion Stage & & & & & 4300 & 10228 \\
\hline Nose Cap & & & & & 1000 & 9228 \\
\hline TPS & & & & & 2928 & 6300 \\
\hline Tail Flare & & & & & 1000 & 5300 \\
\hline Crew Cabin w/ Crew of 4 & & & & & 5300.00 & $\mathbf{0}$ \\
\hline
\end{tabular}

A-2. CTV Reference Profile between LEO Depot and L1 Depot. See Figures 6, 10, 13, 14, and 15 for a typical crew transfer in the CTV from the LEO Depot to the L1 Depot. This profile shows that the CTV was sized for regular transfers between the LEO Depot and the L1 Depot without additional booster requirements. The RUS was sized to match the CTV propellant capacity for standardization. 


\begin{tabular}{|c|c|c|c|c|c|c|}
\hline Event & Delta V & Isp & Mass Ratio & Propellant & Hardware & Mass Remaining \\
\hline Lunar Lander & & & & & 12102 & \\
\hline Refuel & & & & 31018.9 & & 43121 \\
\hline TLI (from L1) & 125.00 & 455 & 1.028 & 1191.2 & & 41930 \\
\hline Lunar Orbit Insert (From L1) & 650 & 455 & 1.157 & $\mathbf{5 6 8 4 . 0}$ & & 36246 \\
\hline ACS & 5 & 310 & 1.002 & 68.9 & & 36177 \\
\hline LS Braking Burn & 1700 & 455 & 1.464 & 13284.1 & & 22893 \\
\hline Final Desc \& Landing & 300 & 310 & 1.070 & 2356.8 & & 20536 \\
\hline Drop Surface Payload & & & & & 1154.16 & 19382 \\
\hline Liftoff & 60 & 310 & 1.014 & 305.8 & & 19076 \\
\hline Ascent to Lunar Orbit (L1) & 2390 & 455 & 1.709 & 8037.6 & & 11038 \\
\hline Rendezvous \& Dock & 25 & 310 & 1.008 & 90.4 & & 10948 \\
\hline Crew \& Effects & & & & & 508 & 10440 \\
\hline Propulsion Stage & & & & & 5953 & 4487 \\
\hline Crew Cabin & & & & & 4487.00 & $\mathbf{0}$ \\
\hline Total Lander Propellant Used & & & & 31018.9 & & \\
\hline Descent Propellant Used & & & & 22585.1 & & \\
\hline Ascent Propellant Used & & & & 8433.8 & & \\
\hline Cryo Impulse Propellant & & & & 28197 & & \\
\hline LOX Impulse Prop. Capacity & & & & 24168.9 & & \\
\hline LH2 Impulse Prop. Capacity & & & & 4028.1 & & \\
\hline LOX Loaded at Launch & & (FYI) & 24652.2 & & & \\
\hline LH2 Loaded at Launch & & (FYI) & 4108.7 & & & \\
\hline Total LOX \& LH2 Loaded at Launch & & & 28760.9 & & & \\
\hline Storable Propellant Used/Loaded & & & 2821.9 & & 2878.36 & \\
\hline
\end{tabular}

A-3. Lunar Lander Reference Profile. See Figure 6 for a typical Lunar Lander mission from the L1 Depot to the surface of the Moon and back to the L1 Depot. The Lander is completely reusable with no separate ascent stage. The propellant capacity is the same as the CTV and RUS for standardization.

\begin{tabular}{|c|c|c|c|c|c|c|}
\hline Event & Delta V & Isp & Mass Ratio & Propellant & Hardware & Mass Remaining \\
\hline \multicolumn{2}{|c|}{ RUS Booster + RUS w/ Payload } & & & & 48652 & \\
\hline Load Propellant & & & & 61466.9 & & 110119 \\
\hline Undock \& Standoff & 20 & 315 & 1.006 & 710.7 & & 109409 \\
\hline TLI-1 & 1380 & 455 & 1.362 & 29105.1 & & 80303 \\
\hline Sep Booster & & & & & 6352 & 73951 \\
\hline TLI-2 & 1820 & 455 & 1.504 & 24769.6 & & 49182 \\
\hline MCC & 25 & 315 & 1.008 & 396.4 & & 48785 \\
\hline L1 Arrival & 425 & 455 & 1.100 & 4432.3 & & 44353 \\
\hline Rend/Dock & 25 & 315 & 1.008 & 357.5 & & 43995 \\
\hline Deliver Payload & & & & & 33500 & 10495 \\
\hline Depart L1 & 425 & 455 & 1.100 & 953.5 & & 9542 \\
\hline Retro LEO (Aerocapture) & 200 & 315 & 1.067 & 598.2 & & 8944 \\
\hline Return to LEO Base & 50 & 315 & 1.016 & 143.6 & & 8800 \\
\hline RUS Empty & & & & & $\mathbf{8 8 0 0}$ & $\mathbf{0}$ \\
\hline \multicolumn{7}{|l|}{ Booster Recovery } \\
\hline & & & & 2052.3 & & 6352 \\
\hline MCC & 200 & 315 & 1.067 & 398.2 & & 5954 \\
\hline Retro into LEO & 1380 & 455 & 1.362 & 1583.9 & & 4370 \\
\hline Rend/Dock LEO Base & 50 & 315 & 1.016 & 70.2 & & 4300 \\
\hline Booster Empty & & & & & 4300 & $\mathbf{0}$ \\
\hline Booster Load & & & & 31868.1 & & \\
\hline Mission Stage Load & & & & 31651.1 & & \\
\hline
\end{tabular}

A-4. RUS Cargo Reference Profile. See Figures 9 and 14 for typical Reusable Upper Stage cargo transfer missions from the LEO Depot to the L1 Depot. This profile utilizes two RUS vehicles to deliver a $33.5 \mathrm{mt}$ cargo from the LEO Depot to the L1 Depot. The second stage RUS has an aerocapture system for use on return to the LEO Depot. Many variations are possible to accommodate payload mass requirements.

18

American Institute of Aeronautics and Astronautics 


\begin{tabular}{|c|c|c|c|c|c|c|}
\hline Event & Delta V & Isp & Mass Ratio & Propellant & Hardware & Mass Remaining \\
\hline \multicolumn{2}{|c|}{ Lander/Ascent Empty w/payload } & & & & 36028 & \\
\hline Load Propellant at L1 & & & & 46015.4 & & 82043 \\
\hline Depart L1 & 425.00 & 455 & 1.100 & 7453.9 & & 74590 \\
\hline TL2I & 166 & 455 & 1.038 & 2724.0 & & 71866 \\
\hline ACS/MCC & 50 & $\mathbf{3 1 5}$ & 1.016 & 1153.9 & & 70712 \\
\hline ESL2 Arrival RUS Burn & 575 & 455 & 1.138 & 8549.6 & & 62162 \\
\hline Separate RUS & & & & 2633.2 & 4300 & 55229 \\
\hline ESL2 Arrival PS Burn & 625 & 455 & 1.150 & 7218.6 & & 48010 \\
\hline Drop ESL2 Payload & & & & & 1000 & 47010 \\
\hline ESL2 Depart & 1200 & 455 & 1.309 & 11085.4 & & 35925 \\
\hline ACS/MCC & 50 & 315 & 1.016 & 576.8 & & 35348 \\
\hline Orbit correction & 200 & 455 & 1.046 & 1549.4 & & 33799 \\
\hline L1 Arrival & 425 & 455 & 1.100 & 3070.7 & & 30728 \\
\hline Habitat Module & & & & & 16200 & 14528 \\
\hline \multicolumn{2}{|l|}{ Prop. Stage Crew Module } & & & & 5300 & 9228 \\
\hline \multicolumn{2}{|l|}{ Nose Cap, TPS \& Flare } & & & & 4928 & 4300 \\
\hline Propulsion Stage & & & & & 4300.00 & 0 \\
\hline RUS Propellant & & & & 22514 & & \\
\hline \multicolumn{2}{|c|}{ Propulsion Stage (PS)Propellant } & & & 23501 & & \\
\hline Sum & & & & 46015 & & \\
\hline Difference & & & & -986 & & \\
\hline \multicolumn{2}{|l|}{ RUS Stage Return inert } & & & & 4300 & \\
\hline Propellant & & & & 2633.2 & & 6933.216543 \\
\hline Turnaround & 1225 & 455 & 1.316 & 1664.5 & & 5268.71 \\
\hline ACS/MCC* & 250 & 315 & 1.084 & 539.0 & & 4729.71 \\
\hline L1 Arrival & 425 & 455 & 1.100 & 429.7 & & 4300.00 \\
\hline RUS Stage & & & & & 4300 & 0 \\
\hline
\end{tabular}

A-5. ESL2 Mission Reference Profile using the RUS, CTV and DSH. See Figure 10 for a typical crew transfer and return from the L1 Depot to service a telescope at the Earth-Sun L2 orbit. This profile uses a RUS, CTV, and a small DSH for the mission. The RUS booster delivers the CTV and DSH to ESL2 and returns to the L1 Depot. The CTV completes the mission and returns the DSH to the L1 Depot for resupply. 


\begin{tabular}{|c|c|c|c|c|c|c|}
\hline Event & Delta V & Isp & Mass Ratio & Propellant & Hardware & Mass Remaining \\
\hline \multicolumn{3}{|c|}{ Cargo Carrier with MOD + RUS Booster stages } & & & 62658 & \\
\hline Load Propellant & & & & 53816.2 & & 116475 \\
\hline Undock \& Standoff & 20 & 315 & 1.006 & 751.7 & & 115723 \\
\hline Depart L1 & 425 & 462 & 1.098 & 10361.8 & & 105361 \\
\hline MCC & 25 & 315 & 1.008 & 849.2 & & 104512 \\
\hline TMI-1 & 800 & 462 & 1.193 & 16916.6 & & 87595 \\
\hline Drop RUS & $\mathbf{0}$ & & & & 6306.4 & 81289 \\
\hline TMI-2 & 250 & 462 & 1.057 & 4364.0 & & 76925 \\
\hline MCC & 25 & 315 & 1.008 & 620.0 & & 76305 \\
\hline Propulsive Capture & 1300 & 462 & 1.332 & 19033.3 & & 57271 \\
\hline Orbit Trim & 50 & 315 & 1.016 & 919.5 & & 56352 \\
\hline RUS (not re-used) & & & & & 9300 & 47052 \\
\hline \multirow[t]{5}{*}{ MOD } & $\mathbf{0}$ & & & & 47051.959 & $\mathbf{0}$ \\
\hline & & \multicolumn{2}{|c|}{ Boost Stage Propellant } & 30886 & 15443 & per RUS \\
\hline & & \multicolumn{2}{|c|}{ Mission Stage Propellant } & 29936.9 & & \\
\hline & & \multicolumn{2}{|c|}{ Extra Propellant } & 5000 & & \\
\hline & & \multicolumn{2}{|c|}{ Total Propellant Load to L } & 65823 & & \\
\hline \multicolumn{7}{|l|}{ Boost Stages Recovery } \\
\hline & & & & 2006.4 & 4300 & 6306.4 \\
\hline Boost Stages Return & 1000 & 462 & 1.247 & 1249.0 & & 5057 \\
\hline MCC & 50 & 315 & 1.016 & 81.2 & & 4976 \\
\hline Periapsis Burn & 200 & 462 & 1.045 & 214.9 & & 4761 \\
\hline MCC & 25 & 315 & 1.008 & 38.4 & & 4723 \\
\hline L1 Arrival & 425 & 462 & 1.098 & 422.9 & & 4300 \\
\hline \multicolumn{2}{|c|}{ Boost Stages (RUS Cluster) } & & & & 4300 & $\mathbf{0}$ \\
\hline & \multicolumn{3}{|c|}{ Boost Stage Propellant Load } & 31812 & & \\
\hline & \multirow{2}{*}{\multicolumn{2}{|c|}{ Transit Prop Used }} & & 3140.5 & & \\
\hline & & & red to L1 & 2520.4 & & \\
\hline
\end{tabular}

A-6. Mars Orbital Depot Delivery Reference Profile. See Figure 14 for MOD delivery and typical cargo missions from Earth through the LEO and L1 Depots to Mars orbit. This profile uses two RUS boosters to deliver the MOD payload to Mars orbit. The first stage RUS booster returns to the L1 Depot. The second stage RUS booster does a propulsive capture at Mars to place the MOD payload into Mars orbit. 


\begin{tabular}{|c|c|c|c|c|c|c|}
\hline Event & Delta V & Isp & Mass Ratio & Propellant & Hardware & Mass Remaining \\
\hline CTV and DSH + RUS Boost stages & & & & & $\mathbf{8 4 8 8 7}$ & \\
\hline Load Propellant & & & & 146900 & & 231787 \\
\hline Undock \& Standoff & 20 & 315 & 1.006 & 1496 & & 230291 \\
\hline Depart L1 & 425 & 453 & 1.100 & 21011 & & 209280 \\
\hline MCC & 25 & 315 & 1.008 & 1687 & & 207594 \\
\hline TMI-1 & 1350 & 453 & 1.355 & 54401 & & 153192 \\
\hline Drop TMI Boost Stages & & & & & 22243.7 & 130949 \\
\hline TMI-2 by CTV & 650 & 453 & 1.158 & 17824 & & 113124 \\
\hline MCC & 25 & 315 & 1.008 & 912 & & 112213 \\
\hline Sep CTV for Aerocapture & & & & & 18696 & 93517 \\
\hline Drop TEI AeroShell & & & & & 4500 & 89017 \\
\hline Post-Aero & 200 & 315 & 1.067 & 5863 & & 83154 \\
\hline Add CTV for Return Trip & & & & & 17373 & 100527 \\
\hline Add TEI Stage & & & & & $\mathbf{0}$ & 100527 \\
\hline Load TEI stage propellant & & & & $\mathbf{0}$ & & 100527 \\
\hline TEI-1 & 1600 & 453 & 1.434 & 30403 & & 70124 \\
\hline Drop TEI-1 & & & & & 4300 & 65824 \\
\hline TEI-2 (CTV) & 500 & 453 & 1.119 & 7007 & & 58817 \\
\hline MCC & 50 & 453 & 1.011 & 785 & & 58032 \\
\hline Separate CTV for Capture \& L1 Arr & & & & & 17373 & 40659 \\
\hline L1 Arrival & 425 & 315 & 1.147 & 5226 & & 35433 \\
\hline Rend/Dock with L1 Depot & 25 & 315 & 1.008 & 286 & & 35147 \\
\hline TEI Stages & & & & & $\mathbf{0}$ & 35147 \\
\hline Deep Space Hab & & & & & 33500 & 1647 \\
\hline TPS & & & & & 5000 & -3353 \\
\hline \multirow[t]{8}{*}{ DSH Propulsion Stage } & & & & & 1147.2012 & -4500 \\
\hline & & \multicolumn{2}{|c|}{ Boost Propellant } & 87938 & 2.7480733 & \\
\hline & & \multicolumn{2}{|c|}{ CTV Propellant } & 28527 & 0.8914668 & \\
\hline & & \multicolumn{2}{|c|}{ TEI Propellant } & 30403 & 0.9501006 & \\
\hline & & \multicolumn{2}{|c|}{ Total Propellant } & 156244 & 4.8826185 & \\
\hline & & & & & & \\
\hline & & \multicolumn{2}{|c|}{ TMI Stages Recovery } & & & \\
\hline & & & & 9344 & 12900 & 22243.7 \\
\hline Boost Stages Return & 1687.5 & 453 & 1.462 & 7030 & & 15214 \\
\hline MCC & 50 & 315 & 1.016 & 244 & & 14969 \\
\hline Periapsis Burn & 200 & 453 & 1.046 & 659 & & 14310 \\
\hline MCC & 25 & 315 & 1.008 & 115 & & 14195 \\
\hline L1 Arrival & 425 & 453 & 1.100 & 1295 & & 12900 \\
\hline \multirow[t]{4}{*}{ Boost Stages (3 RUS) } & & & & & 12900 & $\mathbf{0}$ \\
\hline & & & & & & \\
\hline & & \multicolumn{2}{|c|}{ CTV Aerocapture to MOD } & & & \\
\hline & & & & 1323 & 17373 & 18695.88974 \\
\hline Post-Aero & 200 & 315 & 1.067 & 1172 & & 17524 \\
\hline Rend/Dock with MOD & 25 & 315 & 1.008 & 151 & & 17373 \\
\hline \multirow[t]{4}{*}{ CTV } & & & & & 17373 & \\
\hline & & & & & & \\
\hline & & \multicolumn{2}{|c|}{ CTV Aerocapture to L1 } & & & \\
\hline & & & & 2373 & 15000 & 17373.10251 \\
\hline L1 Arrival & 425 & 315 & 1.147 & 2233 & & \\
\hline Rend/Dock with L1 Depot & 25 & 315 & 1.008 & 140 & & \\
\hline CTV & & & & & 15000 & \\
\hline
\end{tabular}

A-7. Crew Mission Reference Profile to Mars Orbit. See Figure 15 for a typical Crew mission from the L1 Depot to the Mars Orbital Depot with return to the L1 Depot. This profile uses 3 RUS boosters to deliver a CTV, large $D S H$, and an RUS for the TEI maneuver for crew return. The TEI-RUS has an aerocapture system for Mars orbit entry that is then ejected prior to RUS use on return for the TEI maneuver. 


\begin{tabular}{|c|c|c|c|c|c|c|}
\hline \multicolumn{7}{|l|}{ Semi-Cycler } \\
\hline Event & Delta V & Isp & Mass Ratio & Propellant & Hardware & Mass Remaining \\
\hline \multicolumn{2}{|c|}{ CTV + DSH Cycler + RUS Boost stages } & & & & 105674 & \\
\hline Load Propellant & & & & 90191.9 & & 195866 \\
\hline Undock \& Standoff & 20 & 315 & 1.006 & 1264.0 & & 194602 \\
\hline Depart L1 & 425 & 462 & 1.098 & 17424.6 & & 177177 \\
\hline MCC & 25 & 315 & 1.008 & 1428.1 & & 175749 \\
\hline TMI-1 & 1700 & 462 & 1.455 & 54985.3 & & 120764 \\
\hline Separate TMI Stage(s) & & & & & 24252 & 96512 \\
\hline \multirow[t]{2}{*}{ TMI-2 (CTV\#1) } & 250 & 453 & 1.058 & 5281.3 & & 91231 \\
\hline & & & & & $\mathbf{0}$ & 91231 \\
\hline MCC & 25 & 315 & 1.008 & 973.4 & & 90258 \\
\hline Separate CTV\# 1 & & & & & 40983 & 49275 \\
\hline Pick Up CTV\#2 & & & & & 22278 & 71553 \\
\hline \multicolumn{2}{|l|}{ Transfer Propellant to CTV\#2 } & & & $\mathbf{0}$ & & 71553 \\
\hline MCC & 25 & 315 & 1.008 & 397.2 & & 71156 \\
\hline Separate CTV\#2 & & & & & 22278 & 48877 \\
\hline Post-Aero & 200 & 315 & 1.067 & 4460.9 & & 44416 \\
\hline L1 Arr & 425 & 462 & 1.098 & 3977.0 & & 40439 \\
\hline & & & & & & \\
\hline Aerobrake for Hab & & & & & 5000 & 35439 \\
\hline Deep Space Hab & & & & & 33500 & 1939 \\
\hline Storable Propulsion Module & & & & & 1939 & $\mathbf{0}$ \\
\hline \multicolumn{7}{|c|}{ Needs to separate the TMI stage and account for return prop \& transfer tanks } \\
\hline & & & & & 2.70 & 21613.3987 \\
\hline & & \multirow{4}{*}{\multicolumn{2}{|c|}{$\begin{array}{l}\text { Boost Stage Propellant } \\
\text { Spacecraft Propellant } \\
\text { Transferrable propellant } \\
\text { CTV\# } 1 \text { Propellant } \\
\end{array}$}} & 86454 & & \\
\hline & & & & $\mathbf{8 8 3 5}$ & & \\
\hline & & & & $\mathbf{0}$ & & \\
\hline & & & & 31264.5 & & \\
\hline & & \multicolumn{2}{|c|}{ CTV\# 2 Propellant } & 23548.8 & & \\
\hline \multicolumn{7}{|l|}{ Boost Stages Recovery } \\
\hline & & & & 11351.5 & 12900 & 24251.5 \\
\hline TMI stage(s) Return & 2125 & 462 & 1.598 & 9079.5 & & 15172 \\
\hline MCC & 50 & 315 & 1.016 & 243.6 & & 14928 \\
\hline Periapsis Burn & 200 & 462 & 1.045 & 644.7 & & 14284 \\
\hline MCC & 25 & 315 & 1.008 & 115.1 & & 14169 \\
\hline L1 Arrival & 425 & 462 & 1.098 & 1268.7 & & 12900 \\
\hline \multicolumn{2}{|l|}{ Boost Stages (3 RUS, no aero) } & & & & 12900 & $\mathbf{0}$ \\
\hline \multicolumn{7}{|l|}{ CTV Stop \& Go } \\
\hline Event & Delta V & Isp & Mass Ratio & Propellant & Hardware & Mass Remaining \\
\hline CTV-1 Empty with Payload & & & & & 15000 & \\
\hline TEI Propellant & & & & 23550 & & \\
\hline Propellant on board & & & & 2433 & & 40983 \\
\hline \multicolumn{7}{|l|}{ Aerocapture pass } \\
\hline Post-Aero & 200 & 453 & 1.046 & 1804.2 & & 39179 \\
\hline MCC & 25 & 315 & 1.008 & 315.8 & & 38863 \\
\hline Rend \& Dock MOD & 25 & 315 & 1.008 & 313.3 & & 38550 \\
\hline \multicolumn{2}{|c|}{ Top off Propellant from MOD supply } & & & 0.0 & & 38550 \\
\hline Separate from MOD & 25 & 315 & 1.008 & 310.7 & & 38239 \\
\hline TEI & 2350 & 453 & 1.697 & 15708.7 & & 22531 \\
\hline MCC & 50 & 453 & 1.011 & 252.2 & & 22278 \\
\hline \multicolumn{7}{|l|}{ (CTV 2 Joins DSH near Mars) } \\
\hline \multicolumn{7}{|c|}{ (CTV 2 Separates from DSH near Earth) } \\
\hline Earth Arrival Braking & 1060 & 453 & 1.269 & 4729.2 & & 17549 \\
\hline Post-Aero & 200 & 453 & 1.046 & 772.6 & & 16777 \\
\hline MCC & 25 & 315 & 1.008 & 135.2 & & 16641 \\
\hline L1 Arr & 425 & 453 & 1.100 & 1518.3 & & 15123 \\
\hline Rend \& Dock & 25 & 315 & 1.008 & 121.9 & & 15001 \\
\hline CTV & & & & & 15000 & \\
\hline CTV-2 Propellant & & & & 23548.8 & & \\
\hline
\end{tabular}

A-8. Semi-Cycler Crew Mission Reference Profile to Mars Orbit. See Figure 16 for a typical Crew Semi-Cycler mission concept from the L1 Depot to the MOD and return to the L1 Depot. This profile uses three RUS boosters to deliver a CTV and large DSH on a Mars fly-by trajectory. The CTV-1 is swapped with CTV-2 during the fly-by. The aerocapture system on the DSH is utilized on return to the L1 Depot for aero braking into Earth orbit. 


\section{Appendix B}

\section{Nomenclature}

$\begin{array}{ll}\text { ACS } & =\text { Attitude Control System } \\ \text { Aero } & =\text { Aerocapture } \\ \text { Arr } & =\text { Arrival } \\ \text { B } & =\text { Billion } \\ \text { CRV } & =\text { Crew Return Vehicle } \\ \text { Cryo } & =\text { Cryogenic } \\ \text { CTV } & =\text { Crew Transfer Vehicle } \\ \text { Delta-V } & =\Delta v, \text { Change in velocity } \\ \text { Desc } & =\text { Descent } \\ \text { DSH } & =\text { Deep Space Habitat } \\ \text { ELV } & =\text { Expendable Launch Vehicle } \\ \text { EML1 } & =\text { Earth-Moon Lagrange point } 1 \\ \text { ESL2 } & =\text { Earth-Sun Lagrange point } 2 \\ \text { EVA } & =\text { Extra-Vehicular Activity } \\ \text { GEO } & =\text { Geosynchronous orbit } \\ \text { hr } & =\text { hour } \\ \text { Isp } & =I_{\text {sp }} \text {, Specific impulse } \\ \text { ISS } & =\text { International Space Station } \\ \text { kg } & =\text { kilograms } \\ \text { km } & =\text { kilometers } \\ \text { km/s } & =\text { kilometers per second } \\ \text { L1 } & =\text { Earth-Moon Lagrange point } 1 \\ \text { LEO } & =\text { Low-Earth-Orbit } \\ \text { LH2 } & =\text { Liquid Hydrogen } \\ \text { LLO } & =\text { Low-Lunar-Orbit } \\ \text { LOX } & =\text { Liquid Oxygen } \\ \text { LS } & =\text { Lunar Surface } \\ \text { M } & =\text { Million } \\ & \\ & \\ & \end{array}$




\section{Acknowledgments}

David Smitherman thanks the co-author, Gordon Woodcock, for his assistance with the design of the reusable inspace vehicle concepts and his many technical calculations included in Appendix A of this paper for vehicle sizing and propellant requirements. In addition, the authors thank the Advanced Concepts Office at the NASA Marshall Space Flight Center for providing the resources to investigate depots to determine appropriate applications and feasibility.

\section{References}

1 “Saturn V," Wikipedia, URL: http://en.wikipedia.org/wiki/Saturn_V [cited 3 June 2011].

2 "Apollo Command/Service Module," Wikipedia, URL:

http://en.wikipedia.org/wiki/Apollo_Command/Service_Module [cited 3 June 2011].

3 “Apollo Lunar Module," “Wikipedia," URL: http://en.wikipedia.org/wiki/Apollo_Lunar_Module [cited 3 June $2011]$.

${ }^{4}$ Griffin, B., et al., W. Larson and L. Pranke, (ed.), Human Spaceflight: Mission Analysis and Design, McGrawHill Higher Education Series, New York, 2000, Chapter 22, Figure 22-1, "Free Flyer," p. 710.

5 "NASA Budget," Wikipedia, URL: http://en.wikipedia.org/wiki/NASA_Budget [cited 3 June 2011]. 